\title{
STICS: a generic model for the simulation of crops and their water and nitrogen balances. I. Theory and parameterization applied to wheat and corn
}

\author{
Nadine Brisson ${ }^{\mathrm{a}^{*}}$, Bruno Mary ${ }^{\mathrm{a}}$, Dominique Ripoche ${ }^{\mathrm{a}}$, Marie Hélène Jeuffroy ${ }^{\mathrm{a}}$, \\ Françoise Ruget a, Bernard Nicoullaud ${ }^{a}$, Philippe Gate ${ }^{b}$, Florence Devienne-Barret ${ }^{a}$, \\ Rodrigo Antonioletti a , Carolyne Durr ${ }^{\text {a }}$, Guy Richard ${ }^{\text {a }}$, Nicolas Beaudoin ${ }^{\text {a }}$, \\ Sylvie Recous ${ }^{a}$, Xavier Tayot ${ }^{c}$, Daniel Plenet ${ }^{a}$, Pierre Cellier ${ }^{a}$, Jean-Marie Machet ${ }^{a}$, \\ Jean Marc Meynard ${ }^{a}$, Richard Delécolle ${ }^{a}$ \\ a Département environnement et agronomie, Inra, site Agroparc, 84914 Avignon cedex 9, France \\ b Institut technique des céréales et fourrages, France \\ ${ }^{c}$ Agrotransfert Poitou-Charentes, France
}

(Received 13 March 1998; accepted 9 July 1998)

\begin{abstract}
STICS (Simulateur mulTildiscplinaire pour les Cultures $\underline{S}$ tandard) is a crop model constructed as a simulation tool capable of working under agricultural conditions. Outputs comprise the production (amount and quality) and the environment. Inputs take into account the climate, the soil and the cropping system. STICS is presented as a model exhibiting the following qualities: robustness, an easy access to inputs and an uncomplicated future evolution thanks to a modular (easy adaptation to various types of plant) nature and generic. However, STICS is not an entirely new model since most parts use classic formalisms or stem from existing models. The main simulated processes are the growth, the development of the crop and the water and nitrogenous balance of the soil-crop system. The seven modules of STICS development, shoot growth, yield components, root growth, water balance, thermal environment and nitrogen balance are presented in turn with a discussion about the theoretical choices in comparison to other models. These choices should render the model capable of exhibiting the announced qualities in classic environmental contexts. However, because some processes (e.g. ammoniac volatilization, drought resistance, etc.) are not taken into account, the use of STICS is presently limited to several cropping systems. (@ Inra/Elsevier, Paris.)
\end{abstract}

crop modelling / wheat / corn / water balance / nitrogen balance

Communicated by Gérard Guyot (Avignon, France)

* Correspondence and reprints

E-mail: brisson@avignon.inra.fr 


\begin{abstract}
Résumé - STICS : un modèle générique pour simuler les cultures et leurs bilans hydrique et azoté. I. Théorie et paramétrage appliqués au blé et au mails. STICS est un modèle de culture conçu comme un outil de simulation opérationnel en conditions agricoles. Ses variables de sortie sont relatives à la production, à la fois en quantité et en qualité, et à l'environnement. Ses entrées sont relatives au climat, au sol et au système de culture. STICS est présenté comme un modèle montrant les qualités suivantes : robustesse, facilité d'accès aux données d'entrée, souplesse d'évolution par une présentation modulaire et généricité (facilité d'adaptation à divers types de plantes). Pourtant, il ne s'agit pas d'un modèle entièrement nouveau dans les formalismes utilisés. Ils sont, pour Ja plupart, issus de modèles existants. Les grands processus simulés sont la croissance et le développement de la culture ainsi que les bilans hydrique et azoté du système sol-culture. Les sept modules de STICS sont décrits successivement avec une discussion sur les choix théoriques comparés à ceux d'autres modèles : développement, croissance aérienne, composantes du rendement, croissance racinaire, bilan hydrique, environnement thermique de la culture, bilan azoté. IJ ressort que ces choix confèrent à priori au modèle les qualités annoncées dans un contexte environnemental classique. Cependant, l'absence de prise en compte de certains processus (exemples : volatilisation de l'ammoniac, résistance à la sécheresse, ...) restreint pour l'instant son utilisation à certains systèmes de culture. (@ Inra/Elsevier, Paris.)
\end{abstract}

\title{
modélisation de culture / hlé / maiis / bilan hydrique / bilan azoté
}

\section{INTRODUCTION}

During the last decade, crop simulation models, whose principles have been stated by de Wit [49], grew in number within the international scientific community [21, 185]. Regarding wheat and corn, the most used models are CERES-Wheat [135], CERES-Maize [86], ARCWHEAT [184], SWHEAT [176], CORNGRO [42] and SIMTAG [162]. There are also generic models that can be applied to several species, provided that changes in the specific parameter of the crop are made: DAISY [75], SOILN [54], EPIC [186, 187], WOFOST [175]. Despite the notoriety and the availability of existing models, new models appear regularly in the literature $[4,5,30,79,90,99,104,152-154,169$, 178].

Such an abundance of works simply reflects the fact that formalisms and/or simulated processes often have to be modified in order to adapt models to specific environments or to new problems. Indeed, there is no universal crop model, as stated by Sinclair and Seligman [151]. These authors emphasized the heuristic benefit for a group of researchers to build their own model appropriate to their specific purpose, with the possible use of formalisms from existing models.

Nevertheless, crop models are used to solve real problems [23]. Rao and Rees [125], Dái et al. [46] and Stutzcl [166] showed that these models can help farmers to reach a decision about irrigation, sowing time or nitrogen fertilization. Crop models are also largely used at the regional scale for agricultural (e.g. yield assessments) or environmental (e.g. nitrate leaching, crop water requirement) applications $[84,91,109,155,177,179]$. Finally, the assessment of climatic risk (e.g. global change) generally involves the use of crop models: e.g. Hammer and Muchow [74] or Wolf and van Diepen [188].

Generally, the objective and characteristics of the STICS (Simulateur mulTIdisciplinaire pour les Cultures Standard) model fit in with those of many existing models. Its main goal is to simulate the effect of the climate, soil and crop management on the production (amount and quality) and the environment. STICS runs with a daily time step and is capable of integrating spatial and temporal variabitities for successive crops. The main simulated processes are the development and growth of the crop, and the water and nitrogenous balances in the soil and crop.

The novelty of STICS lies in three main features that have influenced its structural design. In contrast to many crop models, STICS was not conceived solely to gather the most recent data. It was constructed as a simulation tool capable of working under agricultural conditions and with readily available spatialized inputs. It is typically an "engineering' model in the meaning given by Passioura [120]. Therefore, we looked for the most robust formalisms in accord with the objective of the model. 
Those formalisms often lie on known analogies or on the simplification of more complex ones. Their parameters are generally few and mostly well known thanks to previous published works. Given that goal, inputs are solely data readily available in agricultural conditions ('a small appetite for data', as stated by Passioura [120]).

STICS was conceived as a generic model, able to adapt easily to various kinds of plant. The formalisms were also chosen for their generic nature. Only a few parameters and some functions describing yield elaboration require some adaptation per species. This paper deals with the modelling adopted for wheat and corn. Nevertheless, the model is being adapted to various kinds of crops: tomato, banana, soybean, catch crop and more, without any change in its structure.

STICS has a modular construction, i.e. a structure made of different modules, with each module representing a process (or a group of processes) occurring in the soil-crop system. This modular nature should render the future evolution of the model easier, as well as the collaboration and transfer of knowledge to related scientific fields [23].

This first paper presents the model and its formalisms. The formalisms are first described and justified model by model, and then compared with the other existent models. Evaluation of the model and its sensitivity will be discussed in a second paper.

\section{GENERAL FEATURES OF THE STICS MODEL}

STICS is a dynamic model, with a daily time step, that simulates the behaviour of the soil-crop system within 1 year. The upper limit of the system is the atmosphere, characterized by standard climatic variables (solar radiation, minimum and maximum temperature, precipitation, reference evapotranspiration) and the lower limit corresponds to the soil/subsoil interface.

The crop is globally characterized by its aboveground biomass (carbon and nitrogen), leaf area index, as well as the number and biomass (carbon and nitrogen) of harvested crop organs. It follows that vegetative organs (leaves, ramifications or stems) are viewed as a whole. The model simulates the behaviour of an average plant, and the stochastic dimension of the crop canopy is not taken into account. The soil is considered as a succession of horizontal layers and each layer is characterized by its content of water, mineral nitrogen and organic nitrogen. Plant roots, which enable the interactions between the soil and the crop, are defined with their length distribution in the soil profile.

STICS simulates the carbon, water and nitrogen balances of the system, and makes it possible to compute agricultural data (yield, input consumption) as well as environmental data (water and nitrate leaching) in various agricultural situations. However, since some processes (e.g. ammoniac volatilization, resistance to drought, soil anoxia, etc.) are not taken into account, the use of STICS is presently limited to cropping systems that do not exhibit those limitations.

Growth is classically driven by the carbon balance [49], i.e. interception of solar radiation by the foliage, then transformation into aboveground biomass (implicitly net photosynthesis + shoot/root partitioning) and, during the final phase of the cycle, into organs to be harvested. Since the nitrogen balance partly depends on the carbon balance, both are simulated at the same time. A thermal index (degree-day), eventually adjusted for photoperiodic and vernalization effects according to the kind of plant, controls the development of the crop. The development model is used to 1) make the leaf area index evolve and 2) define the time when filling of harvested crop organs occurs. The possibility of water or nitrogen stress is accounted for through three indices which can reduce the leaf growth and the radiation use efficiency when nutrition is limited. These indices are computed within the water and nitrogen balances.

STICS was written in FORTRAN 77 and it can be run, under Windows, on any PC compatible microcomputer. In the present paper, FORTRAN notations are used for the variables and the parame- 
ters of the model. All the equations and the list of the symbols are gathered in Appendices 1 and 2.

The model is presented in seven modules: development, shoot growth, yield components, root growth, water balance, thermal environment and nitrogen balance. For each module, a summary of the input parameters and variables in use is given. $\mathrm{A}$ variable differs from a parameter in that it takes a new value at each time step. The parameters independent from the soil, the plant and the crop management are considered as structural parameters and not input parameters. As such, they are just mentioned in the text and referred to in the alphabetic list of Appendix 2. Three types of variables are mentioned: the external driving variables are the standard climatic variables, the internal driving variables come from the other modules and the output variables are calculated within the module.

\section{DEVELOPMENT}

\subsection{Development in STICS}

There are seven development stages that are useful to simulate leaf area index and grain filling ( $f i g$ ure 1 ). The description of the sowing-emergence phase is solely in terms of its duration, allowing the assessment of the occurrence of emergence (ILEV). The emergence determines the beginning of the leaf surface growth. The emergence phase is divided into a phase of seed germination and a phase of epicotile extension. Germination occurs when the sum of degree-days on the sowing, using the soil temperature (TSOL) at the sowing depth (PROFSEM), reaches a given threshold with a condition on soil dryness (equation (1)). The growth rate of the epicotile is assumed to be a logistic function depending on soil temperature at the sowing depth (equation (2) from figure 2). Emergence occurs when epicotile extension is larger than the sowing depth. Lack of germination, as well as death of young plants between germination and emergence, are not taken in account. Consequently, the plant density used as input parameter is a density of emerged plants.

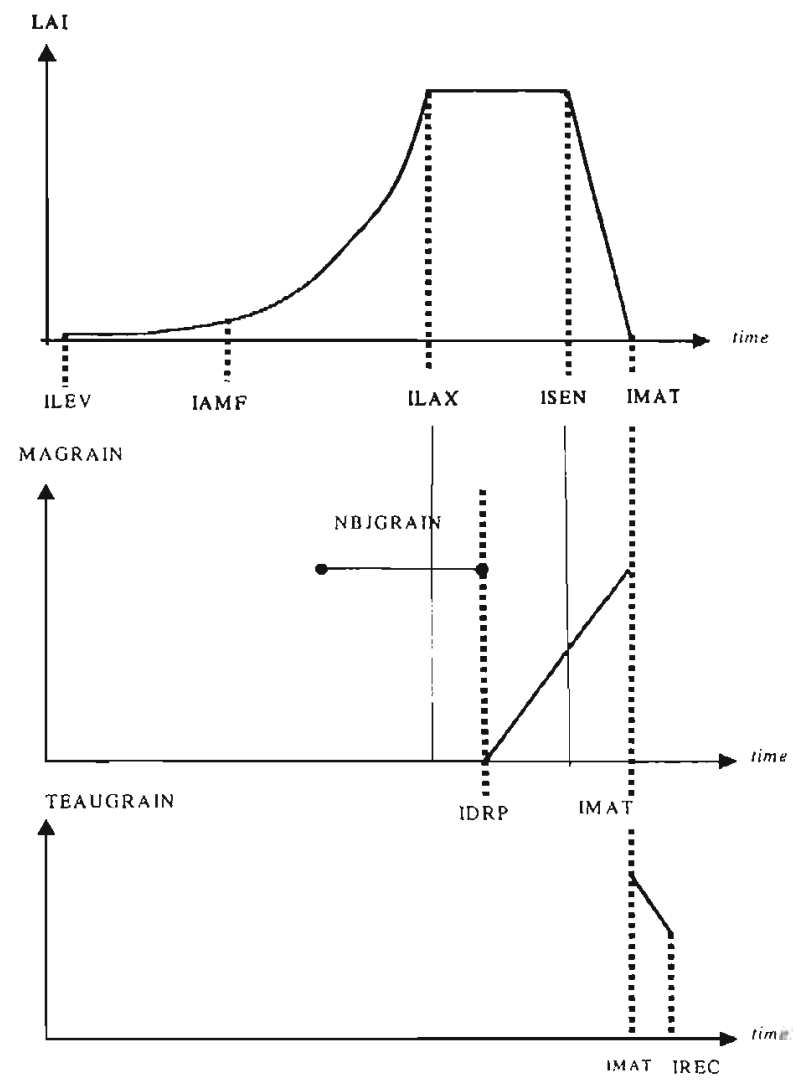

Figure 1. Schematization of the relationships hetween the phasic stages and the evolution of the leaf area index, the grain growth and the grain maturation (the symbols are explained in the text and in Appendix 2).

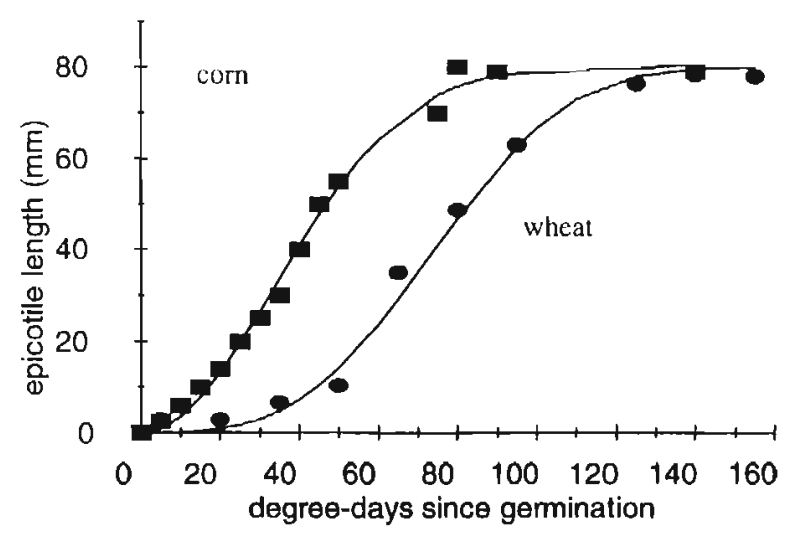

Figure 2. Elongation of the epicotile of wheat (circles) and corn (squares) as a function of the sum of degree-days since sowing. The lines correspond to the equation (2) parametrized as mentioned in table 1 . 
From emergence to physiological maturity, the interval between successive stages is a characteristic of the species and the variety (table $n$ ). It is counted in development units, which mimic the physiological time of the plant. According to the species, during the emergence begining of grain filling phase, these units can be:

- thermal: degree-days (corn)

- photothermal: degree-days x photoperiodic slowing (spring wheat)

- photothermal adjusted for vernalization requirements: degree-days $\mathrm{x}$ photoperiodic slowing $\mathrm{x}$ vernalization slowing (winter wheat)

After grains begin to fill, the development units are degree-days. The daily thermal unit, UDEVCULT, is computed using the temperature of the crop (TCULT calculated in the "thermal environ- ment' module) and two threshold temperatures (equation (3), table $I$ ).

The modelling of photoperiodic and vernalization effects lies in classic concepts [28], and is essentially inspired by the works of Weir et al, [184]. Vernalization requirement is defined as a given number of vernalizing days (JVC), and the vernalizing value of a given day (JVI) is a function of temperature (equation (4)). The summing of vernalizing days begins at the time of germination and requires a minimum of 7 vernalizing days. The vernalization status of the crop (RFVI, equation (5)) increases gradually to reach one. The photoperiodic slowing (RFPI, equation (6)) works between two photoperiod thresholds, PHOBASE and PHOSAT. Regarding wheat, which is a long-day plant, PHOBASE is lower than PHOSAT (table $I$ ). The current photoperiod (PHOI) is computed using the day and the latitudinal position of the crop [146].

Table I. Variables and parameters of the development module.

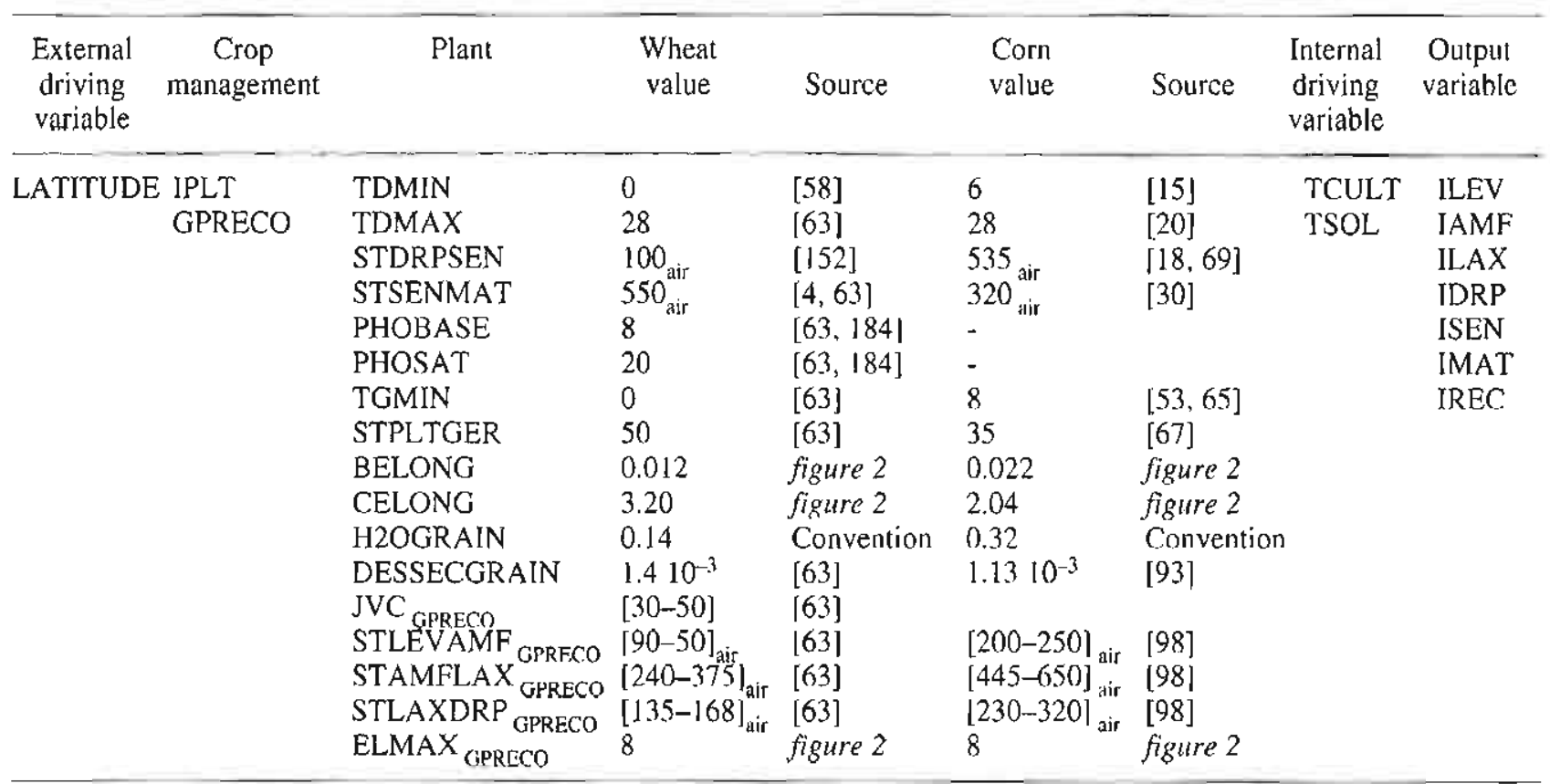

The external driving variables come from the climatic file and the internal driving variables are used in the development module and calculated in another module. The subscript ${ }_{\text {GPRECO }}$ indicates that the parameter is assumed to be genotypedependent and the subscript ${ }_{\text {air }}$ indicates that the degree-days are given in air temperature. Table II gives value to correct them for use in crop temperature. See Appendix 2 for symbols. 
Grains are harvested when dry enough and their dryness depends on the temperatures encountered since physiological maturity (equation (7) and figure 1).

\subsection{Discussion}

As in most crop models, the development stages simulated by STICS can differ from the stages classically defined in agronomic scales. The development stages in STICS are growth stages rather than organogenetic stages [28]. Stages correspond, in fact, to changes in the trophic or morphological strategy of the crop that influences the evolution of leaf area index or grain filling. For example, the stage ISEN does not exist in any phenological scale. It is the period when the senescence of old leaves is no longer compensated by the growth of young leaves, so that, on the whole, the leaf area index decreases. Thus, such stage is very useful in STICS, whereas it is difficult to observe in the field.

Using generic terms for the various stages makes it possible to simulate different species. The stage IAMF (figure 1 ) is the beginning of the stem elongation and is generally not far from the end of leaf initiation [105]: it is the stage 'ear $1 \mathrm{~cm}$ ' for wheat, close to the double-ridge stage [63], whereas it is the floral induction for corn. Like ISEN, the stage ILAX (figure I) must be regarded as a growth stage since it is the result of an equilibrium status between growth and senescence of leaves. In spite of this ambiguity, it is assumed that ILAX can be approached by a thermal (or photothermal) duration. For species of determinate growth, like wheat and corn, the stability of the LAI curve is actually due to the termination of leaf onset. It corresponds to the stage 'last developed leaf' for wheat, close to the booting of stage. For corn, it is between -70 and -78 degree-days (threshold $6^{\circ} \mathrm{C}$ ) before flowering, according to Brisson et al. [30] and Muchow and Carberry [110]. In STICS, the beginning of the grain filling (stage IDRP) coincides with that of the harvest index increase, i.e. the period when grain filling becomes linear. The period between the stages IDRP and ISEN (net senescence of the canopy) (STDRPSEN) is much shorter for wheat than for corn (table $I$ ). This emphasizes the importance of not mixing up IDRP with one of the leaf stages. However, it was assumed that IDRP always occurs during the leaf plateau phase, i.e. between ILAX and ISEN, which is legitimate for the two species of concern.

In the first generation of crop models, the sowing-emergence phase was approached globally and linked to the temperature of the air only, as in models CERES, ARCWHEAT and SUCROS. Thereafter, the effect of the soil water status on the duration of the emergence was also taken in account [90]. Recent works on germination and epicotile extension $[78,81,183$ | now make it possible to distinguish two phases in the emergence. This is the case in the SHOOTGRO model of McMaster et al. [104], in its derivatives (MODWTH3 of Rickman et al. [131]) and in STICS. Such an approach allows the simulated duration of emergence to vary with the three factors temperature, water status of the soil and sowing depth. However, the intluence of these factors on the number of emerged plants is not taken into account in STICS. Moreover, the effects of the water status of the soil is rather brutal through the code variable PFZ (see equation (1)), whereas Alm et al. [3] showed that this phenomenon is more progressive. This effect, in addition to the stopping of root growth in the case of drought (see equation (17)), can hinder the simulations of the cycle beginning in case of drought in the superficial soil layers, especially when sowing is shallow. Finally, although Alm et al. [3] demonstrated that there is a 'soil water status' effect on the epicotile extension stage, this effect was not accounted for in STICS.

The crop (or soi], in the case of emergence) temperature was used to pilot the development clock because many observations showed an acceleration of the cycle in case of drought $[38,51,144,163]$. Indeed, soil drying at the surface as well as at depth causes temperature increases at the plant level [39, 57], which acts upon the progress of the cycle, Ong [117] and Pararajasingham and Hunt [119] showed that it is better to replace the temperature of the air by a temperature close to the plant (soil or organ) to explain the development chronology. We adopted the idea of Idso et al. [80], who suggested to link 
development to the surface temperature rather than to air temperature. These ideas have been applied in other models $[32,82]$.

Through the use of such formalization, the effect of the water deficit on development is linked directly to the temperature and not to a reducing variable ranging between 0 and $\mathrm{I}$. Of course, what is simulated here is an acceleration of the cycle, while some authors speak of delay in the case of early stress acting upon floral induction $[16,144]$. In the short term, the major disadvantage of using crop temperature is that the usual values of threshold temperature or phasic thermal duration can no longer be used [119]. To illustrate this point, we computed durations in both air and crop temperature in two trials (table $I$ ). For the plateau phase, LAX-SEN, the chosen reference temperature has few effects because, in situations of water comfort, the evapotranspiration tends to balance the thermal profile above the canopy. In contrast, during the set up and senescence stages, the contribution of soil or yellow organs to crop temperature (even if roots are in a situation of water comfort) causes an increase of thermal duration calculated with crop temperature.

Although nitrogen nutrition conditions can have an effect on the progress of the cycle and especially on the beginning of net canopy senescence [66], this effect is not considered in STICS.

Since cumulative degree-days are used in STICS, the minimum temperature threshold for development (TDMIN) is assumed constant. However, it was shown that this threshold could vary [6] because the relationship between development rates and temperature is not linear. For example, in the ARCWHEAT model [184] or in Hunt and Pararajasingham [79], various temperature thresholds are used according to the stages. However, since there is a correlation between the duration and the temperature threshold, these parameters are difficult to calibrate.

The vernalization and photoperiod effects are simulated in a classic way $[63,79,184]$. Since the photoperiodic effect (RFPI, equation (6)) works as soon as the emergence occurs, it is assumed that the photosensitivity of wheat is very early, which is a realistic hypothesis for this species [157]. Regarding the tropical corn varieties, a photoperiodic effect may also be used [20].

\section{SHOOT GROWTH}

\subsection{Shoot growth in STICS}

The evolution of leaf area index (LAI) is in four stages (figure I): two phases of growth, one phase of stability and one of senescence. Since the main role of the $\mathrm{LAI}$ in the model is the interception of radiation, it is important that the model could be accurate in the phases of early growth and senescence; for the phase of stability, the requirement of accuracy is less because the interception has

Tahle II. Comparison of the thermal durations of the vegetative phases of STICS expressed either in air temperature (TMOY) or in crop temperature (TCULT) for two trials conducted without water stress under a temperate climate. Wheat was sown in November and corn in April.

\begin{tabular}{ccccc}
\hline Phase & $\begin{array}{c}\text { Example wheat } \\
\text { TMOY }\end{array}$ & $\begin{array}{c}\text { Example wheal } \\
\text { TCULT }\end{array}$ & $\begin{array}{c}\text { Example com } \\
\text { TMOY }\end{array}$ & $\begin{array}{c}\text { Example corn } \\
\text { TCULT }\end{array}$ \\
\hline ILEV-IAMF & 171 & $194(+13 \%)$ & 328 & $415(+26 \%)$ \\
IAMF-ILAX & 350 & $375(+7 \%)$ & 460 & $590(+28 \%)$ \\
ILAX-ISEN & 235 & $251(+7 \%)$ & 765 & $770(+1 \%)$ \\
ISEN-IMAT & 548 & $641(+17 \%)$ & 330 & $400(+21 \%)$ \\
\hline
\end{tabular}

See Appendix 2 for symbols. 
reached its maximum. The net leaf growth (DELTAI), which is computed according to the PUTU model [153], is calculated between stages ILEV and ILAX (equation (8)). A leaf development unit, ULAI, is defined; its value is 1 at emergence and 3 when the leaf area index is maximum (ILAX stage). At the end of the juvenile stage (IAMF), its value is 2.2 [153]. Between these three stages, the model computes a linear interpolation with the development units. The density effect, EFDENSITE (equation (9)), from Singels and de Jagger [153], states that below a given density of plants (BDENS), there is no competition between plants; thus, the leaf surface of plants is independent of the density. Above this density value, the leaf surface of plants decreases in a negative exponential way. The parameter ADENS is the ability of a plant to endure increasing densities. It depends on the species, and possibly on the variety. In the case of wheat, it is the tillering ability. Regarding corn, the parameter BDENS stems from the work by Sonohat Popa [159] while the parameters ADENS and DLAIMAX stem from a specific experimentation (figure 3).

The leaf area index is considered constant between the maximum leaf area index (ILAX) and the beginning of senescence (ISEN) stages. From the beginning of senescence (ISEN) to the physiological maturity (IMAT), the leaf area index decreases linearly. The water stress can cause early senescence and maturity through an increase of crop temperature.

The solar radiation intercepted by the crop (RAINT) follows Beer's Jaw (equation (10)). The accumulation of aboveground biomass (DLTAMS) is a parabolic function of the radiation intercepted by the crop (equation (1I)). This function takes into account the maximum radiation use efficiency (EBMAX), which is specific to each species and can be different during reproductive and vegetative stages. For this parameter, the chosen values are the maximum encountered in the literature (table III, parameters EFCROIVEG and EFCROIREPRO). DLTAMS is also a function of the temperature, through a curve calculated with three cardinal temperatures (equation (12)): TCMIN, TCMAX and TCOPT. The parabolic shape stands for the reduc-

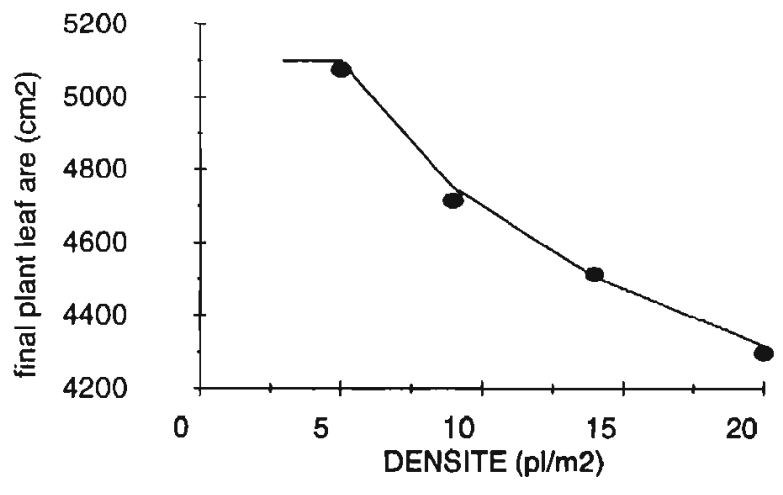

Figure 3. Adjustment by eye of the parameters DI_AIMAX and ADENS for corn. The closed circles represent the measurements and the line for the simulation. The $y$-axis is graduated in individual plant area $\left(\mathrm{cm}^{2}\right)$ at the stage of maximum leaf growth (i.e. LAI max/DENSITE)

tion of the radiation use efficiency for high radiation. The coefficient of the parabola $(-0.0815)$ as well as the shape of the thermal function were computed from the integration over a day of the analytical equation of hourly photosynthesis of the canopy [22] coupled with a respiration model [139]. The effect of temperature on shoot/root partitioning is neglected. The cardinal temperatures that are proposed for wheat and corn (table III) exhibit different physiological thermal windows.

Both water (SWFAC) and nitrogen (INNS) stresses are regarded as acting independently on DLTAMS. The aboveground biomass of the canopy (MASEC) is the sum of DLTAMS values day by day. However, the actual summing begins only when the biomass is higher than a threshold (MSAER0), equal to the amount of biomass allocated to roots at the beginning of the cycle. The parameter MSAER0 was calculated from experimental data unlimited in water and nitrogen, as the ordinate at the origin of linear regressions linking dry matter and intercepted radiation at the beginning of the cycle (figure 4).

\subsection{Discussion}

To assume a direct link between the evolution of LAI and the crop development (figure $l$ ) is a sim- 
Table III. Variables and parameters of the shoot growth module.

\begin{tabular}{|c|c|c|c|c|c|c|c|c|}
\hline $\begin{array}{l}\text { External } \\
\text { driving } \\
\text { variable }\end{array}$ & $\begin{array}{c}\text { Crop } \\
\text { management }\end{array}$ & Plant & $\begin{array}{l}\text { Wheat } \\
\text { value }\end{array}$ & Source & $\begin{array}{l}\text { Corn } \\
\text { value }\end{array}$ & Source & $\begin{array}{l}\text { Internal } \\
\text { driving } \\
\text { variable }\end{array}$ & $\begin{array}{c}\text { Output } \\
\text { variable }\end{array}$ \\
\hline \multirow[t]{10}{*}{ TRG } & DENSITE & DLAIMAX & $4.410^{-4}$ & {$[153]$} & $13.810^{-4}$ & figure 3, [159] & SWFAC & LAI \\
\hline & GPRECO & BDENS & 7 & {$[153]$} & 5 & [159] & TURFAC & MASEC \\
\hline & & EXTIN & 0.50 & {$[4,76,131,154]$} & 0.7 & {$[19,181]$} & INNS & \\
\hline & & TCMIN & 0 & {$[58,63]$} & 8 & {$[53,65,147]$} & TCULT & \\
\hline & & TCMAX & 40 & {$[63,147]$} & 42 & {$[147]$} & ILEV & \\
\hline & & TCOPT & 15 & {$[58,135,186]$} & 25 & {$[186]$} & IAMF & \\
\hline & & EFCROIVEG & 4.25 & {$[1,142]$} & 4.2 & {$[141,165]$} & ILAX & \\
\hline & & EFCROIREPRO & 4.25 & {$[1,142]$} & 3.8 & {$[141,165]$} & ISEN & \\
\hline & & MSAER0 & 1.15 & figure 4 & 1.61 & figure 4 & IMAT & \\
\hline & & ADENS GPRECO & -0.5 & [153] & -0.12 & figure 3 & & \\
\hline
\end{tabular}

The external driving variables come from the climatic file and the internal driving variables are used in the shoot growth module and calculated in another module. See Appendix 2 for symbols.

plification that was also used by Teittinen et al. [169] and Hamer et al. [73]. In a simulation of the 'leaf to leaf' kind [111], classic notions such as phyllotherme and duration of leaf life are used to link the development to LAI, and a distinction is made between growth and leaf senescence. In the model of Jamieson et al. [82], four stages of evolution can be found for LAI, but the two growth stages are different from those in STICS.

In some models, the temperature is the main variable explaining the potential leaf growth, according to the crop development status $[4,75,184,186]$. In other models, the increase of the leaf surface area is a result of the increase in mass by means of the specific surface area [176]. However, the specific surface area is not a constant. It depends on the ratio between structural and non-structural mass [170] and that the ratio varies according to leaf age, temperature [61] and experienced constraints. Consequently, this kind of formalism is generally not very robust.

Many models have a marked preference for 'leaf to leaf' simulation [4, 135, 184]. However, Milroy and Goyne [108] quoted several studies that showed that simulating LAI directly on a canopy scale gives as good results as a 'leaf to leaf' modcl. Baret [11], Milroy and Goyne [108] and Chapman et al. [40]

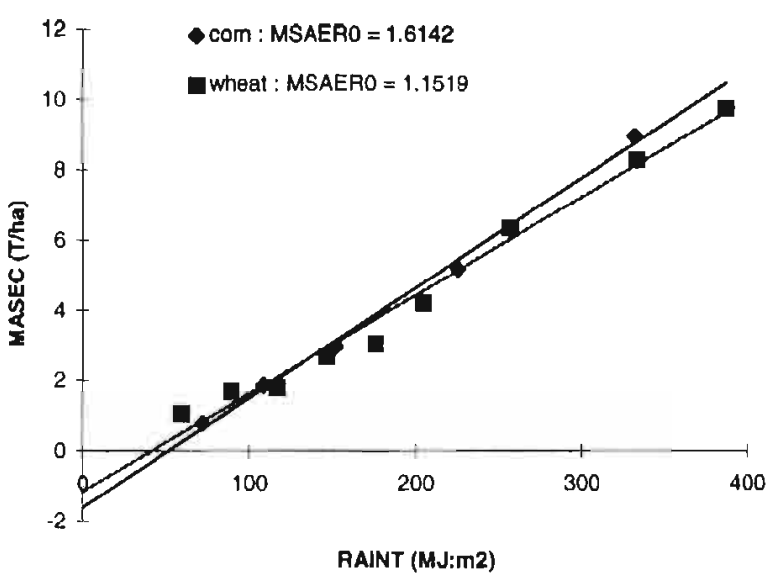

Figure 4. Calculations of the parameter MSARE0 from lincar regression between intercepted radiation (RAINT) and dry matter (MASEC) at the beginning of the crop cycle. Expcrimental data stem from experiments unlimited in water and nitrogen (unpublished data for corn and [129] for wheat).

worked on a canopy scale and they suggested splitting the evolution of LAI into two curves. The first one represents the growth (always a logistic curve) and the other the senescence (logistic or exponential). In STICS, simulating directly the net leaf growth, without splitting the evolution of the LAI into these curves, is another simplification. Such an 
approach results in a raw representation of LAI, with a plateau that does not exist in reality. However, when thinking in terms of efficiency of radiation interception, it appears that there is a plateau [118]

Equation (8), taken from Singels and de Jager [153], reflects the idea that the growth rate of leaves increases together with the development, since DELTAI increases with ULAI. This idea depends on the distinction between leaf initiation and leaf growth stages [104] and on observations that the maximum leaf size increases during the cycle [ 58 , 164] whereas the phyllotherme decreases during the stem elongation [107]. The way of modelling the growth of the leaf surface in STICS is not far from the exponential-linear experimental model proposed by some authors $[72,161]$. These authors have the exponential phase stop at a LAI of 0.7 or 1 ; in STICS, we prefer using a threshold based on the plant development (IAMF stage) rather than a growth threshold. Nevertheless, the value chosen for the parameter STLEVAMF is important to adequately simulate the onset of the leaf canopy.

Competition for the light between plants and its effect on their morphology was analyzed in detail by Yokozawa and Hara [189]. The empirical factor proposed by Singels and de Jager [153] and adopted in STICS (equation (9)) represents globally the negative effect of the sowing density on the elementary growth of the leaf system of each plant. It reflects the acclimation of the plant to the density, either through its tillering (wheat) or through the elementary growth of each leaf (corn). A recent study on corn [159] supports this approach. Chapman et al. [40] applied a similar formalism to the sunflower.

The extinction coefficient (equation (10)) was chosen as 0.5 for wheat and 0.7 for corn. These are averages of values ranging from 0.38 to 0.66 for wheat $[4,76,131,154]$ and from 0.65 to 0.73 for corn $[19,181]$.

The conversion of intercepted radiation into aboveground biomass is subjected to several effects. Most of these effects are multiplying and are therefore assumed to be independent. First, radiation has a saturating effect (equation (11)), which is also present in the model CERES. This effect is the result, even buffered, of the saturation occurring with a short time step at the leaf scale and is easily observed when daily calculations are made with instantaneous formulae of canopy photosynthesis [22]. An effect of the development phase was reported by several authors. Trapani et al. [171] and Muchow et al. [111] observed a decrease in the radiation use efficiency by corn during grain filling, together with a modification of the photosynthesisrespiration balance [139]. In a recent work, Girard [66] showed an opposite trend for wheat: the radiation use efficiency increases at the beginning of the grain filling, as in the pea [83]. In STICS, an ontogenetic effect is used only for the simulation of corn crop (table III). In the case of STICS, the radiation use efficiency (EBMAX) takes into account the allocation of assimilates to the roots. It can be assumed that this allocation stops at the ILAX stage and contributes to increase EBMAX during the filling stage - hence, in opposition to the previous effect. In fact, the trophic-sink function of roots is considered through the parameter MSAER0, at the very beginning of the cycle [96]. The effect of the temperalure on the radiation use efficiency is now classic; it was used, for example, in Sinclair et al,'s models [150]. It is often a diurnal temperature, reconstituted from daily extremes, and this can change the cardinal temperatures in the model (CERES). These temperatures can be different from the thresholds used in the development since the underlying processes are different. As a result of this thermal effect, the order of magnitude of EBMAX is higher than the classic values in the literature [180].

Based on the idea of different sensitivities of physiological functions to the water shortage $[26$, 33], STICS assumes that the effect of water deficits on the growth aboveground (TURFAC in equation (8)) and the radiation use efficiency (SWFAC in equation (11)) is different. Regarding nitrogen, the stress index (INNS) acts similarly on the two basic functions: energy conversion and leaf growth, which is supported by the experimental results of Bélanger et al. [14]. 


\section{YIELD COMPONENTS}

\subsection{The yield components in STICS}

The number of grains is set during a period of variable duration (NBJGRAIN, see figure l), before the beginning of the filling (stage IDRP). This number is set by the mean growth rate of the canopy during this period (equation (13)), according to the species (table IV). The relationships for the two species are shown in figure $5 a$ and $b$.

The dry matter and the nitrogen accumulated in the grains are computed by applying evolutive "harvest indices' to the dry matter and nitrogen content of all aerial parts. These indices, IRCARB and IRAZO, increase as a linear function of the time from the stages IDRP to IMAT (equation (14)). The weight of grains MAGRAIN, and the amount of nitrogen in grains, QNGRAIN, are derived from harvest indices (equation (15)). Then, the weight of each grain is the ratio between the weight and the number of grains, the upper limit being the genetic limit PGRAINMAXI (equation (16)). The values of the parameters VITIRCARB and VITIRAZO are taken from the literature for wheat (table $I V$ ) and from a specific experiment for corn (figure 6). The carbon harvest index is limited to 0.53 (figure 6).

\subsection{Discussion}

In simulation models, the number of viable grains is often linked to the aboveground biomass of the crop at flowering [44] or to the spike biomass at this stage [184]. It is also an important component of agronomic diagnosis [106, 140]. However, many authors consider that, for wheat as well as for corn, the critical period for the setting of the grain number is 20 to 30 days before and after flowering. This period corresponds to the construction of spike structures and it is therefore particularly sensitive to environmental and trophic constraints $[1,55,56$, 172]. The parameters in STICS (table $I V$ ) are taken from specific trials carried out in the French agroclimatic context and the grain yields they reported are higher than those published by Uhart and Andrade [172] and Abbate et al. [1], who worked in Argentina.

The use of an evolutive harvest index (equation (14)) was inspired by the works of Sinclair $[4,111$, $149,160]$. Thus, in STICS, the final harvest index is sensitive only to the duration of the filling. It follows that post-flowering water and nitrogenous stress do not change the evolution of the harvest index, whereas several studies showed that water deficit could produce such a change [143]. However, the duration of grain filling can be shorter in the case of water stress, because the development is controlled by crop temperature. According

Table IV. Variables and parameters of the yield components module.

\begin{tabular}{|c|c|c|c|c|c|c|c|}
\hline $\begin{array}{l}\text { Crop } \\
\text { managemen }\end{array}$ & Plant & $\begin{array}{l}\text { Wheat } \\
\text { value }\end{array}$ & Source & $\begin{array}{l}\text { Corn } \\
\text { value }\end{array}$ & Source & $\begin{array}{l}\text { Internal } \\
\text { driving } \\
\text { variable }\end{array}$ & $\begin{array}{c}\text { Outpul } \\
\text { variable }\end{array}$ \\
\hline \multirow[t]{6}{*}{ GPRECO } & NBJGRAIN & 30 & figure 5 & 20 & {$[97]$} & DLTAMS & MAGRAIN \\
\hline & CGRAIN & 1043 & figure 5 & 152 & figure 5 & MASEC & NBGRAINS \\
\hline & CGRAINV0 & -4160 & figure 5 & 131 & figure 5 & QNPLANTE & PGRAIN \\
\hline & VITIRCARB & 0.011 & [4] & 0.0103 & figure 6 & & QNGRAIN \\
\hline & VITIRAZO & 0.013 & {$[63\rceil$} & 0.0103 & {$[92]$} & & \\
\hline & PGRAINMAXI GPRFCO & {$[34-49] \times 10^{-3}$} & {$[63]$} & {$[27-33] \times 10^{-2}$} & [97] & & \\
\hline
\end{tabular}

The internal driving variables are used in the yield components module and calculated in another module. See Appendix 2 for symbols. 

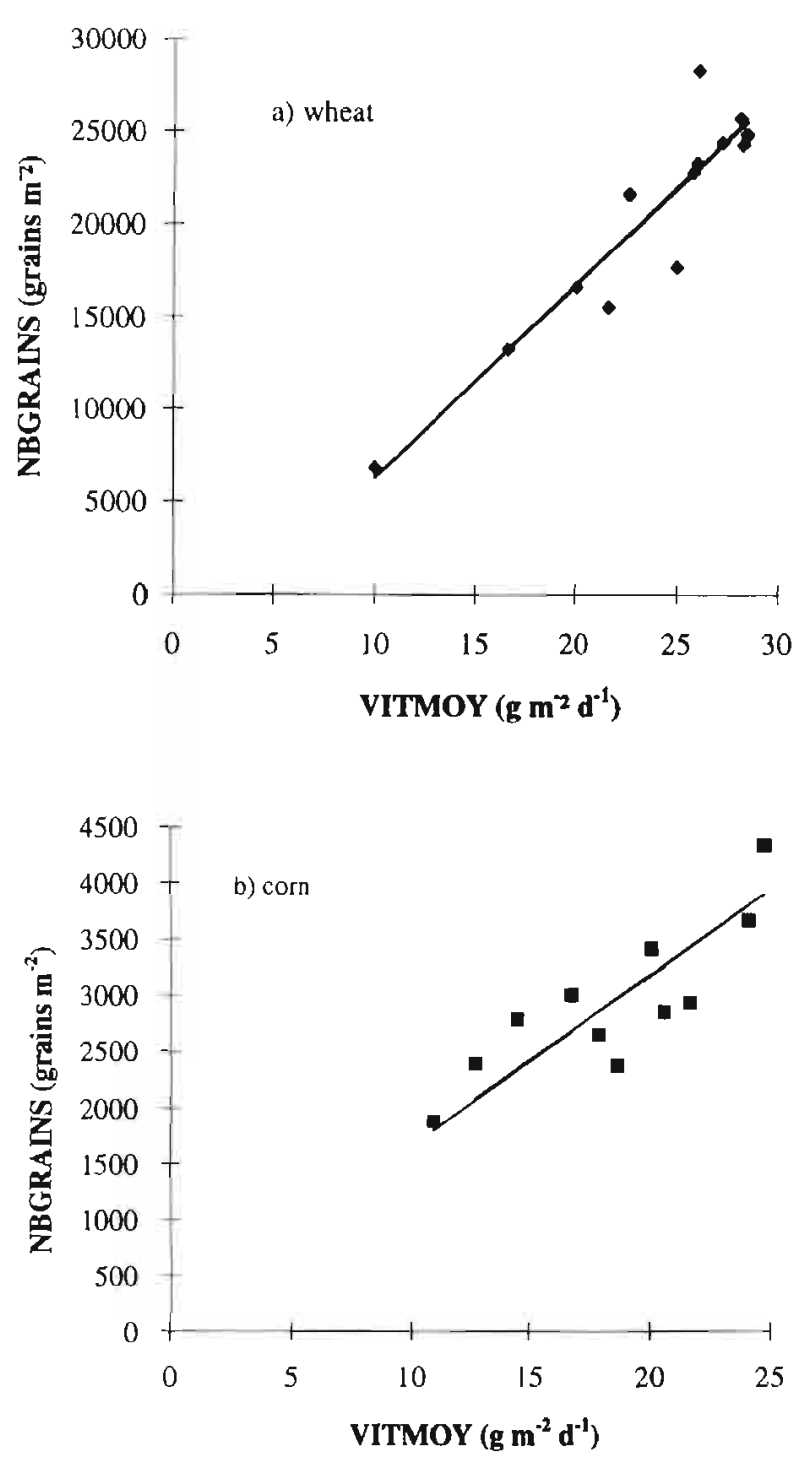

Figure 5. Experimental relationships between grain number (NBGRAINS) and plant growth rate (VITMOY) for wheat (a) and corn (b). The lines are the linear regressions: NBGRAINS $=1043$ VITMOY -4160 for wheat and NBGRAINS $=152$ VITMOY + 131 for corn.

to our experimental results, the daily increase of the harvest index (VITIRCARB) is relatively identical in the two species $\left(0.011\right.$ day $^{-1}$ for wheat and 0.0103 day $^{-1}$ for corn), whereas Muchow et al. [111] suggested a value of 0.15 day $^{-1}$ for corn. For wheat, the parameter VITIRAZO is higher than the equivalent parameter for carbon (VITIRCARB),

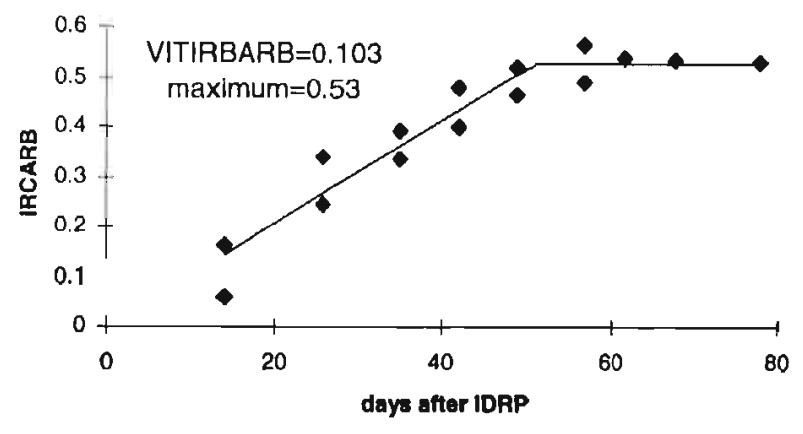

Figure 6. Experimental relationship giving the dynamics of the harvest index (IRCARB) for corn. The line corresponds to a slope (VITIRCARB) of $0.0 \mathrm{I}$ and a threshold of 0.55 .

since grains are preferential sinks for nitrogen, which comes essentially from remobilization. For corn, the same value is affected to both parameters relying on Landry's result [92].

\section{ROOT GROWTH}

\subsection{Root growth in STICS}

In STICS, root growth is not considered in terms of biomass but directly in terms of length. Root growth is assumed to be independent from shoot growth. Actually, the root/shoot biomass partitioning is implicitly accounted for by the radiation use efficiency computed on the basis of aboveground biomass and by the parameter MSAER 0 at the very beginning of the cycle. The role of roots is just to take up water and nitrate. The root profile, effective for the absorption, is determined by the maximum depth reached (ZRAC) and the root density, which has always the same distribution with the depth. The progress rate of the root front (DELTAZ) depends on the species, the crop temperature and the soil water status (equation (17)).

The root front starts its growth at the depth of sowing (PROFSEM) and stops when it reaches the bottom of the soil or when the crop reaches the ILAX stage. If the soil prevents rooting, a fictitious root front is calculated until the stage of physiolog- 
ical stopping (ILAX) is reached. This makes it possible to simulate roots growing over the obstacle (see figure 7) and it is valid in the case of a chemical obstacle or a water table [126].

At each depth reached by the root system (ZRAC), the model creates a profile of effective root density, LRAC (Z), with a sigmoid shape (figure 7), which is computed with the parameters ZLABOUR, ZPRLIM and ZPENTE. Although these parameters, which define the shape of the reference root profile, are important because of their inter-relationships, they do not set the final state of the root system. As can be seen in equation (18), the most important parameters are the differences between ZPENTE and ZLABOUR and especially between ZPRLIM and ZPENTE. ZLABOUR is the depth of tillage, where the proliferation of roots is considered unlimiting for water and mineral absorption, hence an optimal root density (LVOPT). ZPENTE is the depth where the efficiency of root absorption is reduced to $50 \%$ and ZPRLIM is the depth of the root front to which this reference profile can be applied. By varying these three parameters, a fibrous or tap-rooted root system can be built. The threshold of optimal root density (LVOPT) is $0.5 \mathrm{~cm} \mathrm{~cm}^{-3}$ soil [27].

The empirical threshold ZDEMI $=1.4 / \mathrm{S}$ allows at least a $20 \%$ extraction of the water available at the surface. Roots located in dry layers of the soil, with an amount of water equal to or lower than the wilting point, are considered inefficient for the absorption of water.

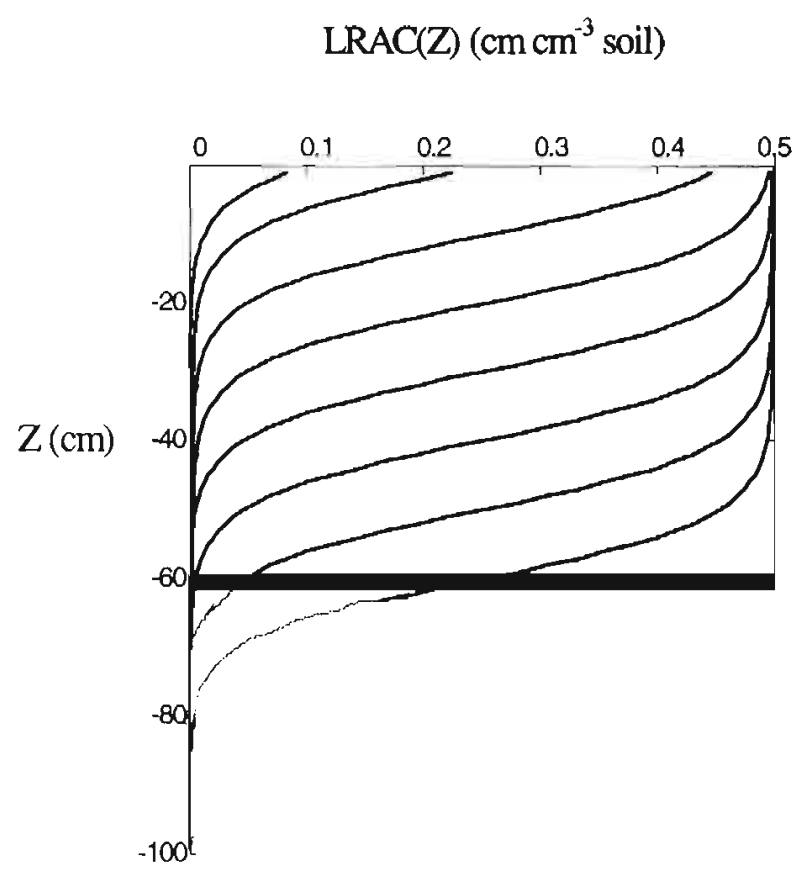

Figure 7. Evolution of the efficient ront density profile (LRAC $(Z)$ ) as a function of the rooting front. The thick line represcnts a rooting obstacle; $Z$ is the depth.

\subsection{Discussion}

Considering the extension of the root system to be independent from the assimilates allocated to the underground compartment is a strong hypothesis. Nevertheless, in STICS the whole extension of the

Table V. Variables and parameters of the root growth module.

\begin{tabular}{lcccccccc}
\hline $\begin{array}{c}\text { Crop } \\
\text { management }\end{array}$ & Soil & Plant & $\begin{array}{c}\text { Wheat } \\
\text { value }\end{array}$ & Source & $\begin{array}{c}\text { Corn } \\
\text { value }\end{array}$ & Source & $\begin{array}{c}\text { Internal } \\
\text { driving } \\
\text { variable }\end{array}$ & $\begin{array}{c}\text { Output } \\
\text { variable }\end{array}$ \\
\hline IPLT & EPC(H) & ZPENTE & 100 & {$[12,114]$} & 90 & $196]$ & ILAX & ZRAC \\
ZLABOUR & & ZPRLIM & 160 & {$[12,114]$} & 140 & {$[96]$} & TCULT & LRAC(Z) \\
PROFSEM & & CROIRAC & 0.12 & {$[63]$} & 0.15 & {$[65]$} & SWFAC & CUMLRACZ \\
& & TCMIN & 0 & {$[63]$} & 8 & {$[65]$} & & \\
\hline
\end{tabular}

The internal driving variables are used in the root growth module and calculated in another module. See Appendix 2 for symbols. 
rool system is not accounted for, but solely its efficient part that is inferior to the actual root length, especially in the upper soil layers. Thus, the link between shoot growth and the extension of the root system could not be immediate.

The volume explored by the root system is set, for the most part, by the progression rate of the root front (CROIRAC, equation (17)), The model is particularly sensitive to this parameter. Unfortunately, there are large variations in values from the literature, due to the various varieties and soil conditions studied (penetrability, fertility, etc.): 0.06 to $0.16 \mathrm{~cm}$ by degree-day for wheat $[63,79]$ and 0.1 to $0.2 \mathrm{~cm}$ by degree-day for com [65].

The water and mineral absorption capacity of the crop depends on the profile of effective root density. Classically, the distribution of roots with depth decreases exponentially [64]. However, many authors $[45,60,89,167]$ have shown that there is a threshold of optimal root density that permits maximal exploitation of the available water. In the surface horizon, the effective root density can reach this threshold but does not exceed it [167]. Consequently, the profile of effective root density was simulated by a logistic function in the model. The threshold used in STICS (LVOPT $=0.5 \mathrm{~cm}$ $\mathrm{cm}^{-3}$ soil) is in agreement with the data of Bonachela [17]. It equates to an average soil-root distance of $0.8 \mathrm{~cm}$, within the interval proposed by Aura [8] (between 0.5 and $1 \mathrm{~cm}$ ). However, Kage and Ehlers [89] and Robertson et al. [136] proposed lower optimal densities $\left(0.1\right.$ and $0.25 \mathrm{~cm} \mathrm{~cm}^{-3}$ soil, respectively).

Using the same threshold of root efficiency for water and nitrogen suggests that their circulation in the rhizosphere is identical or linked. This hypothesis is correct if the mineral nitrogen is in a nitric form (unadsorbed form). It is questionable if the nitrogen absorbed is in an ammoniac form.

\section{WATER BALANCE}

\section{7,1, Water balance in STICS}

The climatic variables used to compute water balance are precipitation (and irrigation) and reference evapotranspiration. The equations for the calculation of the evaporation from the soil and the maximal transpiration were constructed using Penman's reference evapotranspiration [145]; thus, it is better to use this reference. Permanent hydric characteristics of the soil (water content at the field capacity and at the wilting point, bulk soil density) are assumed constant in each horizon. A maximum

Table VI. Variables and parameters of the water balance module.

\begin{tabular}{|c|c|c|c|c|c|c|c|c|c|}
\hline $\begin{array}{l}\text { External } \\
\text { driving } \\
\text { variable }\end{array}$ & $\begin{array}{c}\text { Crop } \\
\text { management }\end{array}$ & Soil & Plani & $\begin{array}{l}\text { Wheal } \\
\text { value }\end{array}$ & Source & $\begin{array}{l}\text { Com } \\
\text { value }\end{array}$ & Source & $\begin{array}{l}\text { Internal } \\
\text { driving } \\
\text { variable }\end{array}$ & $\begin{array}{l}\text { Output } \\
\text { variable }\end{array}$ \\
\hline TETP & AlRG & $\mathrm{HCC}(\mathrm{H})$ & EXTIN & & cf table III & & & LAI & ES \\
\hline \multirow[t]{8}{*}{ TRR } & EFFIRR & HMIN(H) & $\mathrm{KMAX}$ & 1.2 & $\lceil 52\rceil$ & 1.2 & {$[52]$} & ZRAC & $\mathrm{EP}$ \\
\hline & & $\mathrm{DA}(\mathrm{H})$ & PSISTO & 15 & {$[71,165]$} & 12 & {$[168]$} & LRAC (Z) & SWFAC \\
\hline & & ARGI & PSITURG & 4 & {$[165]$} & 5 & {$[24]$} & & TURFAC \\
\hline & & QO & & & & & & & DRAIN \\
\hline & & & & & & & & & $\mathrm{HR}(\mathrm{H})$ \\
\hline & & & & & & & & & HUR(Z) \\
\hline & & & & & & & & & XMLCH 1 \\
\hline & & & & & & & & & RESMES \\
\hline
\end{tabular}

The externaI driving variables come from the climatic file and the internal driving variables are used in the water balance module and calculated in another module. See Appendix 2 for symbols. 
of five horizons with various thicknesses can be defined to characterize the whole soil profile. Summing the thicknesses of horizons makes it possible to determine the soil depth. This depth may possibly prevent rooting (figure 7).

Evapotranspiration of the soil is calculated in two steps. First the potential evaporation related to the energy available at the soil level is calculated and then the calculation of the actual evaporation related to water availability. Potential evaporation from the soil (EOS) is inferred from the reference evaporation using Beer's law (equation (19)). An extinction coefficient weaker than the one in equation (10) is used here; because of near-infrared and long wavelength radiation, the net radiation is higher than the photosynthetic active radiation under the canopy $[121,170]$.

The calculation of the actual soil evaporation (ES) was described in detail in a previous paper [29]. Concepts similar to those developed by Ritchie [132] are used for these calculations. Following rainfall, there are two stages of evaporation. During the first stage, the soil is wet enough for potential evaporation to occur. During the second stage, the evaporation is lower and its decrease (A) depends on a climatic parameter (ACLIM) and the type of soil (amount of clay at the surface and water content at the field capacity). Brisson and Perrier [29] have shown that the parameter ACLIM particularly depends on the speed of the wind during the evaporation stage. The value chosen for ACLIM is 20 , which is equivalent to an average wind speed of $1 \mathrm{~ms}^{-1}$. The transition from the first to the second stage occurs when total evaporation reaches the value $\mathrm{Q} 0$, which is specific for the type of soil. Ritchie [132] found values decreasing between 6 and $12 \mathrm{~mm}$, according to the amount of clay in the surface of the soil, whereas we experimentally determined values between 0 and $22 \mathrm{~mm}$ for Q0 [29]. The evaporation occurring during the second phase is computed in a cumulative manner (equation (20)).

In order to determine the maximum transpiration of the crop, first the evaporation in the crop is calculated as if there was no water shortage of soil and plant surfaces (EO). This evaporation is a logistic function of the leaf area index and makes use of the maximum crop coefficient (KMAX). KMAX is reached when the leaf area index is 5 and it depends on the reference evapotranspiration chosen (equation (21)).

Maximal transpiration depends on the energy available to the plants, which is assessed by subtracting EO from EOS, and on the status of the atmosphere in the vegetation. Many authors have shown that microconvections, caused by the dryness of the soil under the vegetation, increased the water demand of the plants $[50,148]$. From these works, we derived an empirical relationship ([31] and equation (22)), which causes, at the very most, a $40 \%$ increase of EOP when the soil is completely dry. This value is in agreement with the Shuttleworth-Wallace model applied to very dry soil surface conditions [35].

Given the daily time step used in the model, root absorption is assumed equal to leaf transpiration. First, root absorption is calculated on a global scale and thereafter it is distributed to soil layers. This approach is inspired by the work of Cook and Dent [43], who showed that a global calculation of the absorption in the whole rooting zone gives as good results as a calculation of the absorption in each layer. The relative transpiration, i.e. the ratio of actual transpiration to maximal transpiration (EP/EOP), is a bilinear function (equation (23)) of the amount of water available in the rooting zone (TETA). The minimum value of TETA is 0 , when the soil water content is equal to the wilting point (HMIN), while its maximum value is calculated by subtracting the water content at the field capacity (HCC) from that at the wilting point.

The soil water content regarded as being the threshold between the maximal transpiration stage and the reduced transpiration stage depends on root density, stomatal functioning of the plant [156] and climatic demand. Through a simple formalization of root absorption [59], we propose a formula (equation (24)) for this threshold (TETSTOMATE) which takes all these factors into account [27]. When using this formula, the threshold TETSTOMATE tends towards stabilization from a certain root depth (figure 8). 
The water stress indices acting upon plant growth (equations (8) and (11)) are deducted from the previous calculations. The ratio EP/EOP is the index of stomatal stress (SWFAC). The stress index (TUR$F A C$ ), which influences leaf growth, is earlier [26, 108]. Its calculation is similar to that of SWFAC, the critical potential of cellular extension (PSITURG, table VI) being inserted into equation (24). Given that PSITURG is lower than PSISTO, the threshold TETURG is higher. In other words, leaf growth rate can decrease, whereas transpiration is still maximum.

Water transfer into the soil is calculated for each elementary layer of $1 \mathrm{~cm}$, by analogy with a reservoir. Incoming water fills the layers like a cascade, the upper limit of each single reservoir being the field capacity of the layer. The permanent characteristics of elementary layers, as well as the initial amount of water, are deducted from those of the five horizons, which describe the soil.

Regarding the distribution of the water evaporated directly by the soil, the mulch is considered completely dry, whereas the first $5 \mathrm{~cm}$ below are considered partially dry. The mulch (XMLCHI) is a dry layer at the soil surface that results from the advance of the evaporation [29]. The transpiration is distributed in the rooting zone according to the profile of effective root density (LRAC (Z)). If an elementary layer does not provide enough water for evaporation and transpiration, some water is taken in the layer below. However, neither capillary rise nor runoff are explicitly simulated. The layers cannot dry beyond the residual water content, which is defined by the relationship: HA $=$ ARGI / 1500 [29].

To compute TETA, the amount of water available in the soil layers between the surface and the root front is averaged (HUR (Z)-HUMIN (Z)).

\subsection{Discussion}

The various choices for water balance modelling have been discussed in previous papers $[27,29,31]$. Computing the water balance in $1 \mathrm{~cm}$ soil layers may seem unnecessary. However, with this

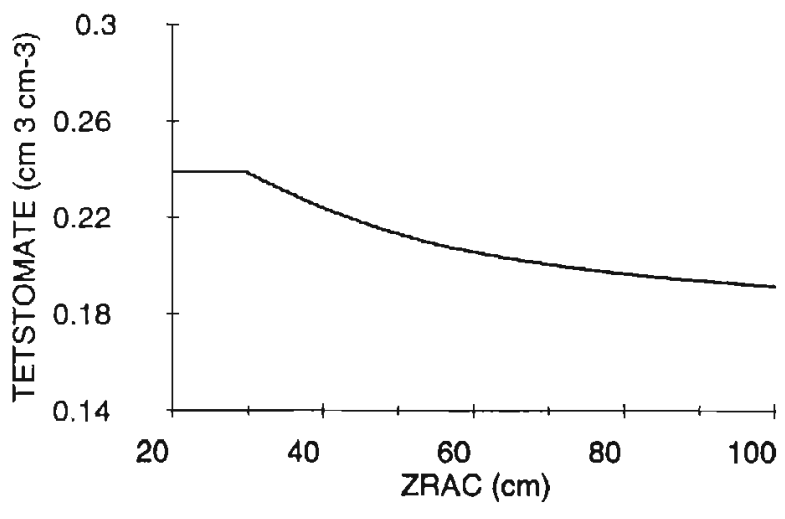

Figure 8. Evolution of the variable TETSTOMATE as a function of the rooting front, ZRAC, tor a clayey-loamy soil, EOP $=4 \mathrm{~mm}$; PSISTO $=15$ bars and a tap-rooted type profile.

approach, not only is there no overload in the parameterization of the soil, but the nitrogen balance is also more precise, since its computation uses concentrations and not global amounts (equation (46)). Moreover, this approach is essential for the validity of the nitrate transfer model. Since this model does not take into account the capillary rise and the runoff, it can give incorrect results in the case of strong edaphic dryness or sloping field.

Regarding the water stress indices, Slabbers [156] and Brisson et al. [31] already proposed to include the threshold of stomatal closing in the formulation of the stress index (SWFAC). In models which use Ritchie's concepts [133], the second stress index, TURFAC, is simply deducted from SWFAC (multiplying factor is 1.5). In STICS, the notion of a water potential threshold acting on the leaf growth (PSITURG) was used in the calculation of TURFAC, in reference to numerous works on the relationship between turgescence and cellular elongation (e.g. $[77,115,116])$.

\section{CROP THERMAL ENVIRONMENT}

\subsection{Crop thermal environment in STICS}

In STICS, the thermal environment of the crop is simulated using the variable TCULT or the temper- 
ature in the soil (TSOL (Z)) for the processes occurring in the soil. Thus, as can be seen in tables I, III and $V$, these variables are driving variables for the thermosensitive mechanisms, while the temperature of the air is not.

The temperature of the crop is computed by means of a simplified energy balance on a daily time scale [7]. This balance takes into account the atmospheric conditions, i.e. standard meteorological data and the crop evapotranspiration, which was calculated in the water balance (table VII). In equation (25), $\mathrm{RA}$ is an averaged daily aerodynamic resistance and is considered constant $\left(\mathrm{RA}=30 \mathrm{sm}^{-1}\right.$ ) and $\mathrm{RN}$ is the daily net radiation computed in equation (26).

The value of the soil albedo falls somewhere between the albedo of the bare soil (ALBSOL) and the albedo of the vegetation, which is 0.23 [134]. The albedo of the bare soil varies with the kind of soil (ALBEDO of the dry soil) and the water content of the surface layer. It increases linearly with the amount of water in the surface layer (equation (27)). This relationship was based on the data of experiments carried out on different types of soil (figure 9).

The average quadratic difference between measurements of surface temperature integrated over a day and the calculations is in the region of $2{ }^{\circ} \mathrm{C}$, without bias [7].

The evolution of the temperature in the soil depends on surface conditions that drive the daily thermal wave, but also on the thermal inertia of the environment. This inertia is responsible for lowering the daily mean temperature at depth in compar-

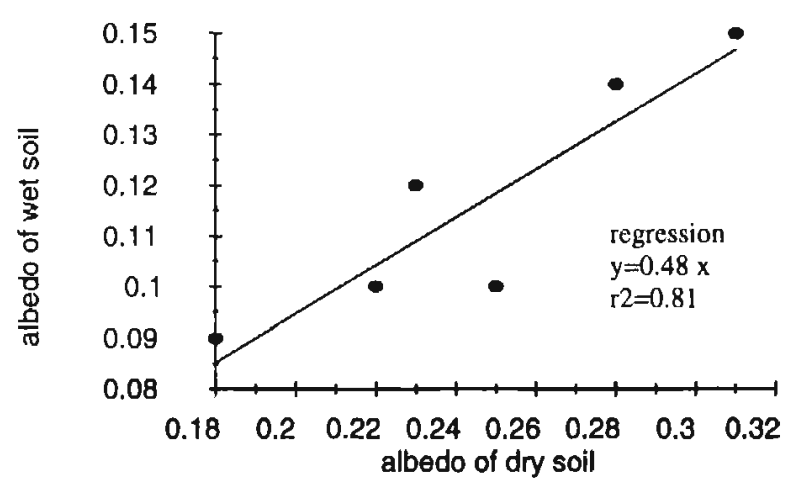

Figure 9. Relationship hetween the albedo of a dry soil (supposed to be at the HUMIN water content) and the albedo of a wet soil (supposed to be at the HUCC water content).

ison with that at surface: it is the annual thermal wave. TCULT is considered as the upper boundary temperature for the calculation of the soil temperature. At depth $Z$, the daily thermal amplitude (AMPLZ), depends on the daily thermal amplitude at the soil surface (equation (28)) and is used to calculate the temperature TSOL (Z). These two variables are calculated according to McCann et al. [102] (equations (29) and (30)). The value of 8.23 (equation (29)) corresponds to a thermal diffusion of $5.3710^{-3} \mathrm{~cm}^{2} \cdot \mathrm{s}^{-1}$, which was calibrated using several soils, under various hydric conditions.

\subsection{Discussion}

Among the original components of STICS, there is the use of canopy evapotranspiration in the cal-

Table VII. Variables and parameters of the thermal module.

\begin{tabular}{lccc}
\hline External driving variable & Soil & Internal driving variable & Output variable \\
\hline TMOY & ALBEDO & EP & TCULT \\
TRG & HMIN(1) & ES & TSOL(Z) \\
& HCC (1) & LAI & \\
& HUR(1) & \\
\hline
\end{tabular}

The external driving variables come from the climatic file and the internal driving variables are used in the thermal module and calculated in another module. See Appendix 2 for symbols. 
culation of a daily energy balance to estimate a daily crop temperature (equation (25)). The calculation of the energy balance with a daily time step, although questionable physically, was performed in the framework of an operational estimation of the water requirements of crops [158]. Another simplification was to assume that the aerodynamic resistance is constant, in order to avoid using wind speed as an input variable. The computation of crop temperature aIso permits to take into account the effects of soil colour and dryness, through the soil albedo (equation (27)). These effects can play an important role in the speed of crop starting, especially during the spring.

\section{NITROGEN BALANCE}

\subsection{Nitrogen balance in STICS}

Nitrogen mineralization is assumed to originate from three pools of decaying organic matter: humified organic matter (HUM), crop residues (RES) and the microbial biomass (BIOM) growing on them. The humified organic matter is mineralized up to a soil depth called PROFHUM. This depth, at least equal to the ploughing depth, allows the model to take into account the contribution of the organic matter located below the ploughed layer in the mineralization process. The mineralization rate of each single layer of the soil, VMINH (Z), is the product of the potential rate of mineralization (VPOT $(Z)$ ), the thermal factors (FTH) and the water content $(\mathrm{FH})$ of this layer (equation (31)). The potential rate is the product of the organic nitrogen pool, NHUM, and the daily potential rate of mineralization K2POT (equation (32)). This mineralization rate depends on the amount of clay and limestone in the soiI (equation (33)). The parameters of equation (33) were computed from experimental data of soil incubations published by Chaussod et al. [41] and Delphin [47] and from results obtained in a crop with a chalky soil [68].

The decay of crop residues in the soil layer in which these residues are mixed (thickness PROFTRAV) results in the mineralization or organization of primary nitrogen and the growth of microbial biomass. In turn, the decay of this microbial biomass produces humus and a secondary mineralization. The daily changes of three carbon pools (RES, BIO, HUM) in each soil layer, up to the depth PROFTRAV, correspond to equations (34) to (36).

The decay rates $\mathrm{KR}$ (equation (37)) and $\mathrm{KB}$ (equation (38)) depend on the quality of crop residues as well as on the temperature and water content of the soil. The carbon assimilation yield of microbes (YRES) is considered constant. The humification rate, HRES (equation (39)), only depends on the quality of the residues, and the quality of crop residues is simply defined by their elementary composition in $\mathrm{C}$ and $\mathrm{N}$, i.e. their $\mathrm{C} / \mathrm{N}$ ratio. The nitrogen mineralization rate linked to the decay of residues (VMINR, equation (40)) is deducted from changes in carbon pools and from $\mathrm{N} / \mathrm{C}$ ratios in these three pools (WR, WB and $\mathrm{WH}$ ).

If the $N / C$ ratios of the residues (WR) and the humus (WH) are constant, the N/C ratio of the microbial biomass (WB) is assumed to depend on the $\mathrm{C} / \mathrm{N}$ ratio of the residues on which microflora grows (equation (41)). Thus, residues with a high $\mathrm{C} / \mathrm{N}$ ratio (e.g. straws of cereals) will be decomposed by a microflora poorer in $\mathrm{N}$ than residues with a low $\mathrm{C} / \mathrm{N}$ ratio (e.g. leaves). This relationship as well as the previous ones (equations (37) to (39)) are based on data from laboratory incubation of various plant residues $[100,128,137]$. The laws of the temperature effect (equations (42) and (43)) were computed on the basis of Recous's work [127]. Two distinct laws are used for the decay of both humus (FTH) and crop residues (FTR). These laws are written according to a reference temperature fixed at $15^{\circ} \mathrm{C}$, by convention. The law of moisture effect (equation (44)) is the same for the two decay processes. It was chosen following a compilation of results from the literature [138].

Inputs of nitrogen in its minetal form (PRECIPN) include synthetic nitrogen fertilizers (urea, ammonium, nitrate) and nitrogen (ammonium, nitrate) from precipitation and irrigation. Nitrogen concentrations of these waters are CONCRR and CONCIRR ( $\left.\mathrm{kg} \mathrm{N} \mathrm{ha}^{-1} \mathrm{~mm}^{-1}\right)$, respectively. 
In equation (45) is introduced the efficiency of the nitrogen fertilizers (EFFN), i.e. the fraction of supplied nitrogen remaining in its mineral form. Two thirds of the complementary fraction (1-EFFN) are attributed to the microbial reorganization, thus increasing the humus pool, while one third contributes to the nitrogen gas losses: volatilization and denitrification.

Transfer of nitric nitrogen in the soil is simulated by a functional, reservoir-type model. Concentrations of nitrogen in the solute of the soil are computed for each elementary layer (equation (46)).

The water draining from a layer $(Z)$ to the layer immediately below $(Z+1)$ carries along a certain amount of nitrate. This nitrate is assumed to mix completely with the water in the layer $\mathrm{Z}+1$. Thereafter, the excess water in this layer (in comparison with the field capacity) drains to the next layer $(Z+2)$ with its new nitrate concentration. The process continues down to the bottom of the profile or to the layer in which the water content remains lower than the field capacity. It is assumed that all the water of the soil can drain. The thickness of the layers $(1 \mathrm{~cm})$ was chosen to be thin enough to reach a convergence during the calculation of the nitrate displacement; that is, similar to a chromatographic elution.

Nitrogen absorption is set up as a comparison between the nitrogen supply of the soil and the nitrogen demand of the crop. The nitrogen demand of the crop is the upper limit of absorption; that is, set by the regulation mechanisms of the plant when the nitrogen supply near the roots is not limiting. This upper limit, DEMAND (equation (47)), is the product of the daily growth rate (DLTAMS) and the derivative of the 'maximum' curve of nitrogen dilution [87].

The parameters of the maximum curve of nitrogen dilution are different for plants in $\mathrm{C} 3$ like wheat [88] and in C4 like corn [124] (table VIII). The curve, established on different crops (wheat, corn, etc.) at vegetative stage, is assumed to be also valid at the reproductive stage.

Nitrogen supply of the soil-root system is equal to the sum of supplies in $1 \mathrm{~cm}$ elementary layers, integrated over the whole root profile. In each layer, the potential flow of nitrogen absorption is decomposed in two flows connected 'in series'. One flow (FLUXSOL) reflects the transport of nitrates to the sites of root absorption. The other (FLUXRAC) is the absorption sensu stricto, involving the active process due to the existence of a system of nitrate transport and to its transport capacity. The transport component FLUXSOL has a diffusive and a convective part. The diffusive flow depends on the root density, the water content and the nitrate concentration of the soil. When the water content is close to the field capacity, the diffusivity coefficient DIFN varies between 0.08 and $0.26 \mathrm{~cm}^{2} \cdot \mathrm{d}^{-1}$, according to some authors $[9,10,103]$. An average value of $0.21 \mathrm{~cm}^{2} \cdot \mathrm{d}^{-1}$ was therefore chosen for STICS. The convective flow is proportional to the transpiration flow and to the nitrate concentration (equation (48)). The biological component, FLUXRAC, is simulated by double enzyme kinetics taking into account transport systems with weak and strong affinity (equation (49)). The parameters VMAXI, KMABS1 and KMABS2 are taken directly from Peuke and Kaiser [122]. The parameter VMAX2 was calculated using data from experiments unlimited in water and nitrogen (figure 10). There is a significant difference between wheat (VMAX2 $=0.05$ ) and com (VMAX2 $=0.017)$. The elementary supply of each layer is equal to the minimum transport and absorption flows. It is then summed over the whole profile to be compared to the demand.

The actual nitrogen absorption is assumed equal to the minimum supply or demand. If the supply is limiting in comparison with the demand, then actual absorption is equal to the supply. In the opposite case, actual absorption is equal to the demand that is distributed in proportion to the elementary supply in each layer, combining transport and absorption abilities (see previous paragraph). The cumulated amount of nitrogen in the plant, QNPLANTE is divided by the dry matter weight in order to compute the nitrogen content of the plant (equation (50)), and then compared to the critical nitrogen concentration of the crop [88]. This critical nitrogen content, below which growth rate decreases, depends on both aboveground biomass and species (equation (51) and table VIII). The nitrogen nutri- 


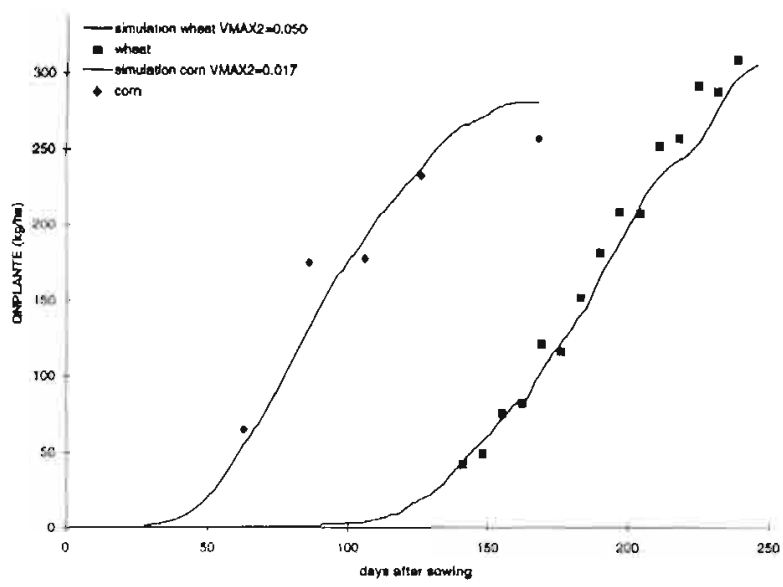

Figure 10. Calculations of the parameter VMAX2 by fitting on data from experiments unlimited in water and nitrogen (unpublished data for corn and [129] for wheat).

tion index, INN [95], and the nitrogen stress index, INNS, are deducted from the previous calculations (equation (52)).

\subsection{Discussion}

The nitrogen module has an appearance of complexity in comparison with the other modules.
Nevertheless, the interactions with the plant, the soil biology and physics are so numerous that it is not possible to treat it simply [48], respecting the objective of correctly predicting the behaviour of nitrogen in the soil-plant system and the amount of nitrate leached. Previous work has shown that nitrogen content in plants may vary by $\pm 70 \%$ from the critical nitrogen content [95]. If the model could not account for these variations by simulating the major processes identified (nitrate movements to the roots, active $\mathrm{N}$ transport, plant demand), it would fail in predicting $\mathrm{N}$ leaching. Considering $\mathrm{N}$ mineralization, our objective also requires not giving up one of the main processes ( $\mathrm{N}$ mineralization from humus, $\mathrm{N}$ mineralization-immobilization from crop residue, microbial growth and decay, modulating effects of water and temperature). Nevertheless, for each of these numerous processes the use of simple relationships made it possible to limit the number of parameters, which is close to a minimum in our mind.

The mineralization model in STICS is a simplified version of a model developed and tested previously [112]. Its principle is rather similar to that developed in the model SUNDIAL [25] or in SOILN [85], considering three compartments of organic nitrogen: crop residue, microbial biomass and humus. However, parameterization being different, it may cause significant differences in the outputs. In those models, the influence of the tem-

Table VIII. Variables and parameters of the nitrogen module.

\begin{tabular}{|c|c|c|c|c|c|c|c|c|c|}
\hline \multicolumn{2}{|c|}{$\begin{array}{l}\text { External Crop } \\
\text { driving management } \\
\text { variable }\end{array}$} & Soil & Plant & $\begin{array}{l}\text { Wheat } \\
\text { value }\end{array}$ & Source & $\begin{array}{l}\text { Corn } \\
\text { value }\end{array}$ & Source & $\begin{array}{l}\text { Internal } \\
\text { driving } \\
\text { variable }\end{array}$ & $\begin{array}{c}\text { Output } \\
\text { variable }\end{array}$ \\
\hline \multirow[t]{8}{*}{ TRR } & ANIT & NORG & ADIL & 5.35 & {$[87,88]$} & 3.40 & {$[123,124]$} & EP & INNS \\
\hline & CONCIRR & ARGI & BDIL & 0.442 & {$[87,88]$} & 0.37 & {$[123,124]$} & $\operatorname{HUR}(\mathrm{Z})$ & $\mathrm{AZ}(\mathrm{H})$ \\
\hline & EFFN & CALC & ADILMAX & 8.47 & {$[87,88]$} & 6.32 & {$[123,124]$} & TSOL(Z) & QNPLANTE \\
\hline & QRES & PROFHUM & BDILMAX & 0.44 & {$[87,88]$} & 0.41 & {$[123,124]$} & LRAC (Z) & QLES \\
\hline & JULTRAV & & VMAXI & 0.0018 & [122] & 0.0018 & {$[122]$} & MASEC & QMINH \\
\hline & PROFTRAV & & KMABS I & 50 & [122] & 50 & [122] & & QMINR \\
\hline & CSURNRES & & VMAX2 & 0.050 & figure 10 & 0.017 & figure 10 & & \\
\hline & & & KMABS2 & 25000 & [122] & 25000 & {$[122]$} & & \\
\hline
\end{tabular}

The external driving variables come from the climatic file and the internal driving variables are used in the nitrogen module and calculated in another module. See Appendix 2 for symbols. 
perature and the water content of the soil on decay rates is accounted for by markedly different functions from that used in STICS. In contrast to the other two models, two different temperature functions are applied to humus and residue decay. Rodrigo et al. [138], comparing nine models, showed that temperature and soil water content action laws vary notably between models and cause strong differences in the simulated net mineralization, without even considering differences in model structures. The parameters governing the decay of the crop residue depend on their quality, which in STICS is assessed solely by their $\mathrm{C} / \mathrm{N}$ ratio. Such a simplifying assumption seems reasonable for simulating carbon dioxide and mineral nitrogen evolution under laboratory conditions of decay. Its validity under field conditions has to be tested. The effect of nitrogen shortage on the decay and immobilization rates is also described differently in the three models. In STICS, it is assumed that the C/N ratio of the microbial biomass increases when mineral nitrogen content of the zone of crop residue incorporation is too low for optimal decay. On nitrogen shortage this effect results in a notable reduced nitrogen immobilization, compared to the situation of potential immobilization calculated with full nitrogen supply. This prediction is consistent with field observations [101].

Regarding the nitrate transfer model, the choice of a 'functional' (terminology of Addiscott and Wagenet [2]) reservoir-type model is probably questionable, though Burns [37], Addiscott and Wagenet [2], Vinten and Redman [182] and Van der Ploeg et al. [174] successfully used this kind of approach. The main limitation of this kind of model is that it does not take explicitly into account the capillary rises of water and nitrate, which can be important in highly conducting soils. In the case of a cultivated soil, this obstacle can be partly overcome if it is assumed that the depth where water and nitrogen are taken up by the plant is a bit deeper than the actual depth of rooting. In order to rigorously simulate the rising flows, it is necessary to work with models that use Darcy's law and the convection-dispersion equation [2]. Though the works on pedotransfer functions (which allow the deduction of the hydrodynamic parameters required for transfer laws from readily available soil data) have developed [36], the variability of the hydrodynamic parameters in space and between soils is still difficult to assess [173]. Consequently, these models are difficult to use and to parameterize. Several studies have shown that the transfer of nitrate could be simulated with a functional as well as with a mechanistic model, provided that the dispersivity is weak and that the thickness of elementary layers is small $[174,182]$. On the other hand, it is clear that our functional model cannot simulate precisely, and with a small enough time step, the water content of surface layers and their porosity to the air. Consequently, the model cannot estimate the nitrogen losses from denitrification and it is no longer valid when these losses are potentially important (hydromorphous soil).

On the one hand, it is a classic approach to compare supply and demand in the model of nitrogen absorption by root [48]. On the other hand, the calculation of the demand is more original since it is based on the maximum curve of crop dilution [87]. This curve is clearly distinct from the 'critical' curve [95], the latter making it possible to determine precisely if there is - or not - a nitrogen stress. The extrapolation of these curves to the reproduction stage is an important simplification, more or less justified depending on the plant $\lceil 113$, 123]. The need to consider two completely different critical curves for herbaceous plants in $\mathrm{C} 3$ and $\mathrm{C} 4$ was demonstrated several years ago [70] and confirmed recently [88, 124]. The modelling of the soil supply may also be considered as a simplification of more mechanistic models, since it simulates both the transfer of nitrogen from the soil to the root through diffusion and convection and the active nitrogen absorption by the root system. Although this description has the advantage of dealing with well iclentified mechanisms, it may appear too complex to some. Yet, it needs only a small number of parameters: one of diffusion and two couples of parameters (VMAX, KMABS), each characterizing the two systems of nitrate absorption (with high and low affinity for nitrate) which were discovered recently [122]. Our simulations showed that none of these two absorption systems could be neglected in the simulation of the global absorption. Split-root 
experiments have shown that half of the root system can be sufficient to meet the demand of the whole plant. Such experimental facts can be explained by an increase of nitrate transporters in the zones of high concentration that would correspond to a differentiation in the parameters VMAX. In that case, STICS is incorrect because it assumes that VMAX is constant. However, even with this simplification the model is able to simulate the same level of nitrate absorption with a homogeneous as well as with a heterogeneous (with the same global quantity) distribution of nitrate. This results from the fast system of absorption (of low affinity) increasing the rate of absorption in the zones of high concentration while in the zone of low concentration only the slow system (of high affinity) is active. Hence, the low affinity system is active just after fertilization and the high affinity system takes over when nitrate concentrations in the soil decrease significantly. Nevertheless, the nitrogen absorption is difficult to simulate because it highly depends on the validity of the model that describes the expansion and the evolution of root density.

The nitrogen stress index is directly linked to the satisfaction of needs (or INN). Bélanger et al. [14] and Gastal et al. [62] showed that this hypothesis is true when INNS is higher than 0.4 .

\section{CONCLUSION}

The formalisms adopted in the STICS model try to answer two antagonistic demands [120]: the use of easily accessible parameters and a structure true to the reality. For some mechanisms, the choice was made easier by previous works showing that simple formalisms are interesting and have robustness. It was, for example, the case of water balance [94] and the evolutive crop index (works from Sinclair and colleagues $[4,111,149,160])$. For some other mechanisms the choices were more original (nitrogen balance, raising, leaf area index, crop temperature) and therefore they have to be tested in various experimental situations and through an analysis of sensitivity. (This will be discussed in a second work).
For those reasons there appears to be some unbalance in the complexity of the various modules. However, is it possible to reach the same level of simplification or analogy for all the biophysical processes addressed in a crop model? In practice, it appears that complexity is not measurable by the number of equations but by the cost of parameters required to feed them. The inputs required to run the model are divided into climatic, crop management, soil and plant. Specialists must supply the plant parameters as well as some soil parameters. For the rest, all the information is readily available, which makes the STICS model easy to use.

The parameterization adopted stem from the literature or from specific trials carried out in the context of agronomic applications of STICS. Such context excludes the situations that are not anticipated by the model: strong drought, permanent presence of ammonium in soils, hydromorphous soils, manure supply, sloping field and shortage of nutrients other than nitrogen.

The generic and modular qualities of STICS are currently tested by applying all or a part of the model to other crops, e.g. banana [34], pea, barley, rape [13], tomato [130], sorghum and forage crops in various environments (tropical and temperate).

STICS can be considered as a multidisciplinary platform for progressive and balanced integration of the main processes relating to production and environment.

Acknowledgements: I am particularly grateful to my colleagues from the AgroPedoClimatic Unit of Inra in Guadeloupe, who made my 1-year visit so pleasant, allowing me to write this paper. I would like to thank Eric Tamigneaux for the English translation of the text.

\section{REFERENCES}

[1] Abbate P.E., Andrade F.H., Culot J.P., The effects of radiation and nitrogen on number of grains in wheat, J. Agric. Sci. 124 (1995) 351-360.

[2] Addiscott T.M., Wagenet R.J., Concepts of solute leaching in soils: a review of modeling approaches, $\mathrm{J}$. Soil Sci. 36 (1985) 411-424. 
[3] Alm D.M., Stoller E.W., Wax L.M., An index model for predicting seed germination and emergence rates, Weed Technol. 7 (1993) 560-569.

[4] Amir I., Sinclair T.R., A model of the temperature and solar-radiation effects on spring wheat growth and yield, Field Crop. Res. 28 (1991) 47-58.

[5] Amir J., Sinclair T.R., A model of water limitation on spring wheat growth and yield, Field Crop. Res. 28 (1991) 59-69.

[6] Angus J.F., Mackenzie D.H., Morton R., Schafer C.A., Phasic development in field crops. II. Thermal and photoperiodic responses of spring wheat, Field Crop. Res. 4 (1981) 269-283.

[7] Antonioletti R., Brisson N., Estimation de la temperature radiative d'un couvert en moyenne journalière, in : Publication de l'Association Internationale de Climatologie, vol. 9, Actes du colloque de Strasbourg, 1996.

[8] Aura E., Modelling non-uniform soil water uptake by a single plant root, Plant Soil 186 (1996) $237-$ 243.

[9] Baldwin J.P., Nye P.H., Tinker P.B., Uptake of solutes by multiple root systems from soil. III. A model calculating the solute uptake by a randomly dispersed root system developing in a finite volume of soil, Plant Soil 38 (1973) 621-635.

[10] Barber S.A., Silberbush M., Plant root morphology and nutrient uptake, in: Roots, Nutrient and Water Influx, and Plant Growth, ASA special publication, 49 (1984) 65-87.

[11] Baret $F$., Contribution au suivi radiométrique des cultures de céréales, thèse, Université d'Orsay, France, $1986,182 \mathrm{p}$.

[12] Barraclough P.B., Kuhlmann H., Weir A.H., The effects of drought and nitrogen on root growth and water uptake by winter wheat, in: Scaife A. (Ed,), First Congress of the European Society of Agronomy, Paris, 5-7/12/1990, European Society of Agronomy, Colmar, Session $1003,1990$.

[13] Beaudoin N., Makowski D., Mary B., Wallach D., Pardoneau V., Parisseaux B., Machet J.M., Meynard J.M., Evaluation de l'impact économique et environnemental de la mesure agri-environnementale « réduction d'intrants " au moyen de modèles agronomiques, Rapport interne, 1997

[14] Bélanger G., Gastal F., Lemaire G., Growth analysis of a tall fescue sward fertilized with different rates of nitrogen, Crop Sci. 32 (1992) 137l-1376.
[15] Bloc D., Gouel J.P., Influence des sommes de température sur la floraison et la maturité du maïs, Ann. Amelior. Plant. 28 (1977) 89-111.

[16] Blum A., Crop responses to drought and the interpretation of adaptation, Plant Growth Regul. 20 (1996) 135-148.

[17] Bonachela S., Root growth of triticale and barley grown for grain or for forage-plus-grain in a Mediterranean climate, Plant Soil 183 (1996) 239-251.

[18] Bonhomme R., Derieux M., Heat units requirements for maize hybrids in Europe. Results of the European FAO sub-network. II. Period from silking to maturity, Maydica 27 (1982) 79-96.

[19] Bonhomme R., Ruget F., Derieux M., Vincourt $P .$, Relations entre production de matière sèche aérienne et énergie interceptée chez différentś génotypes de maïs, C.R. Acad. Sci. III-Vie 294 (1982) 393-398.

[20] Bonhomme R., Derieux M., Edmeades G.O., Flowering of diverse maize cultivars in relation to temperature and photoperiod in multilocation field trials, Crop Sci. 34 (1994) 156-164.

[21] Bonhomme R., Drouet J.L., Améglio T., Introduction à la modélisation du fonctionnement physiologique d'un couvert, in : Actes de l'école chercheurs Inra en bioclimatologie, Le Croisic, 3-7 avril 1995. 1. De la plante au couvert végétal, 1995, pp. 647-667.

[22] Boote K.J., Jones J.W., Equations to define canopy photosynthesis from quantum efficiency maximum leaf rate light extinction LAI and photon flux density, in: Biggins J. (Ed.), Progress in Photosynthesis Research. Proceedings of the VIlth International Congress on Photosynthesis, Providence, Rhode Island, USA, 10-15 August 1986, 1987, pp. 415-418.

[23] Boote K.J., Jones J.W., Pickering N.B., Potential uses and limitations of crop models, Agron. J. 88 (1996) $704-716$.

[24] Boyer J,S., Differing sensitivity of photosynthesis to low leaf water potentials in corn and soyabean, Plant Physiol. 46 (1970) 236-239.

[25] Bradbury N.J., Whitmore A.P., Hart P.B.S., Jenkinson D.S., Modelling the fate of nitrogen in crop and soil in the years following application of $15 \mathrm{~N}$ labelled fertilizer to winter wheat, J. Agric. Sci. 121 (1993) 363-379.

[26] Bradford K.J., Hsiao T.C., Physiological responses to moderate water stress, in: Physiological Plant Ecology, vol. II, Springler-Verlag, Berlin, New Series 12B, 1993, pp. 263-324. 
[27] Brisson N., An analytical solution for the estimation of the critical soil water fraction for the water balance under growing crops, Hydrology Earth Syst. Sci. (1998) (accepted for publication).

[28] Brisson N., Delécolle R, Développement et modèles de simulation de culture, Agronomie 12 (1991) 253-263.

[29] Brisson N., Perrier A., A semi-empirical model of bare soil evaporation for crop simulation models, Water Resour. Res. 27 (1991) 719-727.

[30] Brisson N., King D., Nicoullaud B., Ruget F., Ripoche D., Darthout R., A crop model for land suitability evaluation: a case study of the maize crop in France, Eur, J. Agron. 1 (1992) 163-175.

[31] Brisson N., Seguin B., Bertuzzi P., Agrometeorological soil water balance for crop simulation models, Agric. For. Meteorol. 59 (1992) $267-287$.

[32] Brisson N., Casals M.L., Antonioletti R., Gate P., ARJBLE: un modèle dynamique de blé dur qui simule certains mécanismes de résistance à la sécheresse. 16th International Congress on Irrigation and Drainage, Le Cuire, 15-20/09/1996, 1996.

[33] Brisson N., Bonhomme R., Ameglio $T_{\text {., Gautier }}$ H., Olioso A., Drouet J.L., Modèle de culture : simulations sous contraintes à partir d'un potentiel de production, in : Cruizial P., Lagouarde J.P. (€d.), Inra, Departement de Bioclimatologie, Service de formation permanent, tome 2, Du couvert végétal ì la petite région agricole, Ecole chercheurs Inra en bioclimatologie, Le Croisic, 3-7/4/1996, 1997.

[34] Brisson N., Dorel M., Ozier-Lafontaine $H_{\text {., }}$ Effects of soil management and water regime on the banana growth between planting and flowering. Simulation using the STICS model. Proceedings of IHS Colloque, Tenerife, November 1997, 1997

[35] Brisson N., Itier B., L'Hotel J.C., Lorendeau J.Y., Parameterisation of the Shuttleworth-Wallace model to estimate daily maximum transpiration for use in crop models, Ecol, Model. 107 (1998) 159-169.

[36] Bruand A.. Duval O., Wösten J.H.M., Lilly A., The use of pedotransfer in soil hydrology research in Europc. Proceedings of the Second Workshop of the Projed 'Using Existing Soil Data to Derive Hydraulic Parameters for Simulation Modelling in Environmental Studies and in Land Use Planning', Orléans, France, 1012/10/1996, 1997. $211 \mathrm{p}$.

[37] Burns I.G., Equations to predict the leaching of nitrate uniformly incorporated to a known depth or uniformly distributed throughout a soil profile, J. Agric. Sci. 86 (1976) 305-313.
[38] Casals M.L., Introduction des mécanismes de résistance à la sécheresse du Blé dur au fonctionnement phénologique et trophique de la plante dans un modèle dynamique de croissance, thèse de doctorat, Ina-PG, $1996,130 \mathrm{p}$.

[39] Cellier P., Ruget F., Chartier M., Bonhomme R., Estimating the temperature of a maize apex during early growth stages, Agric. For. Meteorol. 63 (1993) 35-54.

[40] Chapman S.C., Hammer G.L., Palta J.A., Predicting leaf area development of sunflower, Field Crop. Res. 34 (1993) 101-112.

[41] Chaussod R., Nicolardot B., Catroux G., Chrétien J., Relations entre les caractéristiques physicochimiques et microbiologiques de quelques sols cultivés, Sci. Sol 2 (1986) 213-226.

[42] Childs S.W., Gilley J.R., Splinter W.E., A simplified model of corn growth under moisture stress, Trans. ASAE 20 (1977) 858-865.

[43] Cook H.F., Dent D.L., Modelling soil water supply to crops, Catena 17 (1990) 25-39.

[44] Cordery I., Graham A.G., Forecasting wheat yields using a water budgeting model, Aust. J. Agric. Res. 40 (1989) 715-728.

[45] Cowan I.R., Transport of water in the soil-plant atmosphere system, J. App]. Ecol. 2 (1965) 221-239.

[46] Dai Q., Fletcher J.J., Lee J.G., Incorporating stochastic variables in crop response models. Implications for fertilization decisions. Am. J, Agric. Econ, 75 (1993) $377-386$.

[47] Delphin J.E., Evaluation du pouvoir minéralisateur de sols agricoles en fonction de leurs caracteristiques physico-chimiques, Agronomie 6 (1986) 453458 .

[48] de Willigen P., Nitrogen tumover in the soilcrop system; comparison of fourteen simulation models, Fert. Res. 27 (1991) 141-149.

[49] de Wit C.T., Simulation of assimilation respiration and transpiration of crops, Simulation Monographs. Pudoc, Wageningen, 1978.

[50] Denmead O.T., Relative significance of soil and plant evaporation in estimating evapotranspiration, in: Plant Response to Climatic Factors. Proceedings Uppsala (Sweden) Symposium, UNESCO, Paris, 1970 , 1973, pp. 505-511.

[51] Desclaux D., Roumet P., Impact of drought stress on the phenology of two soybean (Glycine max L. Mert) cultivars, Field Crop. Res. 46 (1996) 61-70. 
[52] Doorenbos J., Kassam A.H., Réponse des rendements à l'eau, Bull. FAO d'irrigation et de drainage 33 (1987) $235 \mathrm{p}$.

[53.] Durr C.+ Boiffin J., Boizard H., Influence du régime thermique sur la croissance pondérale et le rythme d'apparition des feuilles de jeunes plants de mails, in : Picard D. (éd.). Physiologie et production du maìs, Pau, 13-15 novembre 1990, 1991, pp. 83-90.

[54] Eckersten H., Jansson P.E., Modelling water flow, nitrogen uptake and production for wheat, Fert. Res. 27 (1991) 313-329.

[55] Fischer R.A., Growth and water limitation to dryland wheat yield in Australia: a physiological framework. J. Aust. Inst. Agric. Sci. 45 (1979) 83-94.

[56] Fischer R.A., Stockman Y.M., Kernel number per spike in wheal (Triticum aestivum $\mathrm{L}$ ): responses to preanthesis shading, Aust. J. Plant Physiol. 7 (1980) $169-180$.

[57] Friend A,D., Use of a model of photosynthesis and leaf microenvironment to predict optimal stomatal conductance and leaf nitrogen partitioning, Plant Cell Environ. 14 (1991) 895-905.

[58] Gallagher J.N., Field studies of cereal leaf growh. I. Initiation and expansion in relation to temperaturc and ontogeny, J. Exp. Bot. 30 (1979) 625-636.

[59] Gardner W.R, Dynamic aspects of water availability to plants, Soil Sci. 89 (1960) 63-73.

[60] Gardner W.R., Modeling water uptake by roots. Irrigation Sci. 12 (1991) 109-I 14.

[61] Gary C., Jones J.W., Longuenesse J.J., Modelling daily changes in specific leaf area of tomato: the contribution of the leaf assimilate pool, Acta Hortic. 328 (1993) 205-210.

[62] Gastal F., Bélanger G., Lemaire G., A model of the leaf extension rate of tall lescue in response to nitrogen and temperature, Ann. Bot. 70 (1992) 437-442.

[63] Gate P., Ecophysiologie du blé : de la plante à la culture, ITCF \& Lavoisier, Paris 1996, 429 p.

[64] Gewitz A., Page E.R., An empirical mathematical model to describe plant root systems, J. Appl. Ecol. 1) (1974) $773-781$.

[65] Giauffrel C., Derieux M., Variabilité génétique de la croissance de la jeune racine en fonction de la température, in : Picard D. (éd.), Physiologie et production du maís, Pau, 13-15 novembre 1990, 1991, pp. 69-74.

[66] Girard M.L., Modélisation de l'accumulation de biomasse et d'azote dans les grains de ble tendre d'hiver (Trificum aestivam L.) : simulation de leur teneur en protéines à la récolte, thèse de doctorat, Ina-PG, 1997, $96 \mathrm{p}$.
[67] Girardin P., George F., Influence sur la germination de la concentration en azote dans l'environnement immédiat de la semence de maïs, in : Picard D. (éd.), Physiologie et production du maïs, Pau, 13-15 novembre 1990, 1991, pp. 61-68.

[68] Gosse G., Cellier P., Denoroy P., Gabrielle B.,

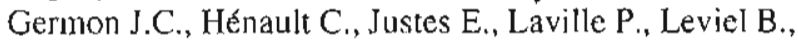
Mary B., Nicolardot B., Recous S., Bilan environnemental du colza. Rapport de fin de contrat, Inra-CetionAdeme, 1997, $119 \mathrm{p}$.

[69] Goytino R., Gay J.P., Importance respective des périodes de formation de remplissage et de maturation du grain dans la composition du rendement, in : Picard D. (éd.), Physiologie et production du maïs, Pau, 13-15 novembre 1990, 1991, pp. 207-214.

[70] Greenwood D.J., Lemaire G., Gosse G., Cruz P., Draycott A., Neeteson J.J., Decline in percentage $\mathrm{N}$ of C3 and C4 crops with increasing plant mass, Ann. Bot. 66 (1990) 425-436.

[71] Guichard S., Peut-on mettre on évidence un acclimatalion à la séchercsse du fonctionnement hydrique du blé dur? DEA Université Montpellier, 1996, $15 \mathrm{p}$.

(72) Hakebotté B., Winter, oilseed rape. Analysis of yield formation and crop type design for higher yield potentials, Ph.D. thesis, Wageningen Agricultural University, Wageningen, The Netherlands, 1996, $156 \mathrm{p}$.

[73] Hamer P.J.C., Carr M.K. V., Wright E., Crop production and water use. III. The development and validation of a water-use model for potatoes, J. Agric. Sci. 123 (1994) 299-311.

[74] Hammer G.L., Muchow R.C., Assessing climatic risk to sorghum production in water-limited subtropical environments, 1. Development and testing of a simulation model, Field Crop. Res. 36 (1994) 221-234.

[75] Hansen S., Jensen H.E., Nielsen N.E., Swenden H., DAISY, A Soil Plant System Model. Danish simulation model for transformation and transport of energy and matter in the soil plant atmosphere system. The National Agency for Environmental Protection, Copenhagen, 1990 , pp. 369.

[76] Hodge T., Kanemasu E.T., Modeling daily matter production of winter wheat, Agron. J. 69 (1977) 974978 .

[77] Hohl M., Schopfer P., Growth at reduced turgor - irreversible and reversible cell-wall extension of maize coleoptiles and its implications for the theory of cell growth, Planta 87 (1992) 209-217.

[781 Hucl P., Effects of temperature and moisture stress on the germination of diverse common bean genotypes, Can. J. Plant Sci. 73 (1993) 697-702. 
[79] Hunt L.A., Pararajasingham S, CROPSIMWHEAT: a model describing the growth and development of wheat, Can. J. Plant Sci, 75 (1995) 619-632.

[80] Idso S.B., Jackson R.D., Reginato R,J, Extending the 'degree-day' concept of plant phenological development to include water stress effects, Ecology 59 (1978) $431-433$

[81] Itabari J.K., Gregory P.J,, Jones R.K, Effects of temperature soil water status and depth of planting on germination and emergence of maize (Zea mays) adapted to semi-arid eastern Kenya, Exp. Agric. 29 (1993) $351-364$.

[82] Jamieson P.D., Brooking I.R., Porter J.R., Wilson D.R., Prediction of leaf appearance in wheat: a question of temperature, Field Crop. Res. 41 (1995) 3544.

[83] Jeuffroy M.H., Ney B., Crop physiology and productivity, Field Crop. Res. 53 (1997) 3-16.

[84] Johnson A.K.L., Cramb R.A., Development of a simulation based land evaluation system using crop modelling expert systems and risk analysis, Soil Use Manage. 7 (1991) 239-246.

[85] Johnsson H., Bergström L., Jansson P.E., Paustian K., Simulated nitrogen dynamics and losses in a layered agricultural soil, Agric. Ecosyst. Environ. 18 (1987) $333-356$.

[86] Jones C.A., Kiniry J.R., CERES-Maize, A Simulation Model of Maize Growth and Development, Texas A\&M University Press, College Station, TX, 1986.

[87] Justes E., Mary B., Meynard J.M., Machet J,M, Thelier-Huché L., Determination of a critical nitrogen dilution curve for winter wheat crops, Ann. Bot. 74 (1994) $397-407$.

[88] Justes E., Jeuffroy M.H., Mary B., II. The nitrogen requirement of major agricultural crops. Wheat, barJey and durum wheat, in: Lemaire G. (Ed.), Diagnosis of the Nitrogen Status in Crops, Springer-Verlag, Berlin 1997, pp. 73-91.

[89] Kage H., Ehlers W., Does transport of water to roots limit water uptake of ficld crops? Z. Pflanz, Bodenkunde 159 (1996) 583-590.

[90] Kanneganti V.R., Fick G.W., A warm-season annual grass growth model parameterized for maize and sudangrass, Agric. Syst. 36 (1991) 439-470.

[91] Lal H., Hoogenboom G., Calixte J.P., Jones J.W., Beinroth F.H., Using crop simulation models and Gis for regional productivity analysis, Trans. ASAE 36 (1993) $175-184$.
[92] Landry J., Accumulation des protéines dans le grain de maîs, in : Gallais A. (éd.), Physiologie du maïs, Royan, 15-17 mars 1983,1984 , pp. 287-302.

[93] Ledent J.F., Mouraux D., Suivi de la croissance du grain par une technique de microéchantillonage, in : Picard D. (éd.), Physiologie et production du maís, Pau, 13-15 novembre 1990, 1984, pp. 253-258.

[94] Leenhardt D., Voltz M., Rambal S., A survey of several agroclimatic soil water balance models with reference to their spatial application, Eur. J. Agron. 4 (1995) $1-14$.

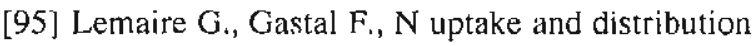
in plant canopies, in: Lemaire G. (Ed), Diagnosis of the Nitrogen Status in Crops, Springer-Verlag, Berlin 1997, pp. 3-44.

[96] Lemaire G., Charrier X., Hébert Y, Nitrogen uptake capacities of maize and sorghum crops in different nitrogen and water supply conditions, Agronomie 16 (1996) 231-246.

[97] Lorgeou J., Evolution du poids d'un grain et de sa teneur en eau, in : Picard D. (éd.), Physiologie et production du mais, Pau, 13-15 novembre 1990, 1991, pp. 259-274.

[98] Lorgeou J., Des références pour les variétés, in : Picard D. (๕d.), Physiologie et production du maïs, Pau, 13-15 novembre 1990, 1991, pp. 291-306.

[99] Maas S.J., Parameterized model of gramineous crop growth. 1. Leaf area and dry mass simulation, Agron. J. 85 (1993) 348-353.

[100] Mary B., Fresneau C., Morel J.L., Mariottj A., $\mathrm{C}$ and $\mathrm{N}$ cycling during decomposition of root mucilage, roots and glucose in soil, Soil Biol. Biochem. 25 (1993) $1005-1014$.

[101] Mary B., Recous S., Darwis S., Robin D., Interactions between decomposition of plant residues and nitrogen cycling in soil, Plant Soil 181 (1996) $71-$ 82 ,

[102] McCann I.R., Mcfarland M.J., Witz J.A., Nearsurface bare soil temperature model for biophysical models, Trans. ASAE 34 (1991) 748-755.

[103] McCaski]l M.R., Blair G.J., A model of S, P and $\mathrm{N}$ uptake by a perennial pasture, Fert. Res. 22 (1990) $161-172$.

[104] McMaster G.S., Klepper B., Rickman R.W., Wilhem W.W., Willis W.O., Simulation of shoot vegetative development and growth of unstressed winter wheat, Ecol. Model. 53 (1991) 189-204, 
[105] McMaster G.S., Morgan J.A., Wilhelm W.W., Simulating winter wheat spike development and growth, Agric. For. Meteorol. 60 (1992) 193-220.

[106] Meynard J.M., Sebillotte M., L'élaboration du rendement du blé, base pour l'étude des autres céréales à talles. Elaboration du rendement des principales cultures annuelles. Combe L., Picard D. (éd.), Inra Paris, 1994, pp. 31-51.

[107] Miglietta F., Effect of photoperiod and temperature on leaf initiation rates in wheat (Triticum spp.), Field Crop. Res. 21 (1) (1989) 21-130.

[108] Milroy S.P., Goyne P.J., Leaf area development in barley-model construction and response to soil moisture status, Aust. J. Agric. Res. 46 (1995) 845-860.

[109] Moen T.N., Kaiser H.M., Riha S.J., Regional yield estimation using a crop simulation model: concepts, methods and validation, Agric. Syst. 46 (1994) 79-92.

[110] Muchow R.C., Carberry P.S., Phenology and leaf-area development in a tropical grain sorghum, Ficld Crop. Res. 23 (1990) 22I-237.

[111] Muchow R.C., Sinclair T.R., Bennett J.M., Temperature and solar radiation effects on potential maize yield across locations, Agron. J. 82 (1990) 338343.

[112] Néel C., Modélisation couplée du transfert et des transformations de l'azote : paramétrisation et évaluation d'un modèle en sol nu, thèse de doctorat, Université Paris VI, France, 1996, 196 p.

[ | 13] Ney B., Doré T., Sagan M., The nitrogen requirement of major agricultural crops. Grain legumes, in: Lemaire G. (Ed.), Diagnosis of the Nitrogen Status in Crops, Springer-Verlag, Berlin 1997, pp. 107-117.

[114] Nicoullaud B., Darthout R., Duval O., Etude de l'enracinement du blé tendre d'hiver et du maïs dans les sols argilo-limoneux de petite Beauce, Etude et Gestion des Sols 2 (1) (1995) 83-200.

โ115\} Nonami H., Boyer J.S., Primary events regulating stem growth at low water potentials, Plant Physiol. 93 (1990) 1601-1609.

[116] Nonami H., Boyer J.S., Direct demonstration of a growth-induced water potential gradient, Plant Physiol. 102 (1993) 13-19.

[117] Ong C.K., Response to temperature in a stand of pearl millet (Pennisetum typhoides S \& H). I. Vegetative development, J. Exp. Bot. 34 (1983) 332336.
[118] Otegui M.E., Nicolini M.G., Ruiz R.A., Dodds P.A., Sowing date effects on grain yield components for different maize genotypes, Agron. J. 87 (1995) 29-33.

[119] Pararajasingham S., Hunt L.A., Wheat spike temperature in relation to base temperature for grain filling duration, Can. J. Plant Sci. 71 (1991) 63-69.

[120] Passioura J.B., Simulation models: science snake oil education or engineering? Agron. J. 88 (1996) 690-694.

[121] Perrier A., Net radiation and energy budget of a surface of land canopy, Colloque Franco-Israelien : bilan des rayonnements ct agriculture, Bet Dagan (Israel) 28/3-2/4 1971, 1971.

[122] Peuke A.D., Kaiser W.M., Nitrate or ammonium uptake and transport, and rapid regulation of nitrate reduction in higher plants, Prog. Bot. 57 (1996) 93-113.

[123] Plénet D., Fonctionnement des cultures de maïs sous contrainte azotée. Détermination et application d'un indicc de nutrition, thèse de docteur, INPL, Université de Nancy, France, 1995, 115 p.

[124] Plénet D., Cruz P., The nitrogen requirement of major agricultural crops. Maize and sorghum, in: Lemaire G. (Ed.), Diagnosis of the Nitrogen Status in Crops, Springer-Verlag, Bcrlin 1997, pp. 93-106.

[125] Rao N.H., Rees D.H., Irrigation scheduling of rice with a crop growth simulation model, Agric. Syst. 39 (1992) l 15-132.

[126] Rebière B., Effet d'un excès d'eau sur la croissance d'une culture de blé d'hiver, thèse de doctorat, Université de Strasbourg, France, 1996, 214 p.

[127] Recous S., Réponse des matières organiques des sols aux changements globaux, Doss. Environ. Inra 8 (1995) /2-18.

[128] Recous S., Robin D., Darwis S., Mary B., Soil inorganic $N$ availability: effect on maize residue decomposition, Soil Biol. Biochem. 27 (1995) 1529-1538.

[129] Recous S., Jeuffroy M.-H., Mary B., Meynard J.-M., Gestion de l'azote en zone d'agriculture intensive. Rapport final Inra-Grande Paroisse S.A., 1996, 37 p.

[130] Régat M., Etude et modélisation de l'élaboration du rendement de la tomate à croissance déterminée en milieu tropical, Rapport de DEA, 1997, 25 p.

[131] Rickman R.W., Waldman S.E., Klepper B., MODWhi3: a development-driven wheat growth simulation, Agron. J. 88 (1996) 176-185.

[132] Ritchie J.T., Model for predicting evaporation from a row crop with incomplete cover, Water Resour. Res. 8 (1972) 1204-1213. 
[133] Ritchie J.T,, Soil water availability, Plant Soil 58 (1981) 327-338.

[134] Ritchie J.T., A user-oriented model for the soil water balance in wheat, in: Fry E., Atkin T.K. (Eds.), Wheat Growth and Modeling, Plenum Publishing Corp., NATO-ASI Series, 1985, pp. 293-305.

[135] Ritchie J.T., Otter S., Description and performance of CERES-Wheat, a user-oriented wheat yield model, USDA-ARS-SR Grassland Soil and Water Research Laboratory, Temple, TX, 1984, pp. 159-175.

[136] Robertson M.J., Fukai S., Ludlow M.M., Hammer G.L., Water extraction by grain sorghum in a sub-humid environment. 2. Extraction in relation to root growth, Field Crop. Res. 33 (1993) 99-112.

[137] Robin D., Effet de la disponibilité en azote sur les flux de carbone et d'azote au cours de la décomposition des résidus végétaux dans les sols, thèse de doctorat, Ina-PG, Paris. 1994, 143 p.

[138] Rodrigo A., Recous S., Néel C., Mary B., Modeling temperature and moisture effects on C-N transformations in soils: comparison of nine models, Ecol. Model. 102 (1997) 325-339.

[139] Ruget F., Respiration de croissance et respiration d'entretien : méthodes de mesure comparaison des résultats, Agronomic 7 (1981) 601-610.

[140] Ruget $F$, Elaboration du rendement chez le maïs. Elaboration du rendement des principales cultures annuelles, Combe L., Picard D. (éd.), Inra, Paris, 1994, pp. $73-83$.

[141] Ruget F., Bonhomme R., Varlet-Grancher C., Analyse de la fonction de photosynthèse dans CERESMaize, in : Picard D. (éd.), Physiologie et production du maïs, colloque INRA/AGPM/, Université Paris-Sud, Pau, 13-15/11/1990, Inra, Paris, 1991, pp. 446-453.

[142] Ruget F., Nicoullaud B., Lorgeou J., Brisson N., Gate P., Ripoche D., King D., Delecolle R., Daroussin J., Ngongo L., Clastre P., Délimitation de zones aux potentialités équivalentes en France et dans la Communauté Européenne pour optimiser les téseaux d'expérimentation des variétés de blé et de maïs, Ruget F. (éd.), Inra, Avignon, 1995, $52 \mathrm{p}$.

[143| Sadras V.O., Connor D.J., Physiological basis of the response of harvest index to the fraction of water transpired after anthesis - a simple model to estimate harvest index for determinate species, Field Crop. Res. 26 (1991) 227-239.

[144] Seghieri J, Floret C., Pontanier R., Plant phenology in relation to water availability - herbaceous and woody species in the savannas of Northern Cameroon, J. Trop. Ecol. 11 (1995) 237-254.
[145] Seguin B., Etude comparée des méthodes d'estimation d'ETP en climat méditerranéen du sud de la France (région d'Avignon), Ann. Agron. 26 (1975) 671691.

[146] Sellers W.D., Physical Climatology, University of Chicago Press, Chicago, IL, 1965, 272 p.

[147] Shaykewich C.F., An appraisal of cereal crop phenology modeling, Can. J. Plant Sci. 75 (1995) 329341 .

[148] Shutleworth W.J., Wallace J.S., Evaporation from sparse canopy - an energy combination theory, Q. J. Roy. Meteor. Soc. 111 (1985) 839-855.

[149] Sinclair T.R., Water and nitrogen limitations in soybean grain production. I. Model development, Field Crop. Res.15 (1986) I25-141.

[150] Sinclair T.R., Mosca G., Bona S., Simulation analysis of variation among seasons in winter wheat yields in northern Italy, J. Agron. / Crop Sci. / Z. Acker Pflanzenbau 170 (1993) 202-207.

[151] Sinclair T.R., Seligman N.G., Crop mudeling: from infancy to maturity, Agron. J. 88 (1996) 698-704.

[152] Singels A., de Jager J.M., Refinement and validation of the PUTU wheat crop growth model. 1. Phenology, S. Afr. J. Plant Soil 8 (1991) 59-66.

[153] Singels A., de Jager J.M., Refinement and validation of the PUTU wheat crop growth model. 2. Leaf area expansion, S. Afr. J. Plant Soil 8 (1991) 67-72.

[154] Singels A., de Jager J.M., Refinement and validation of the PUTU wheat crop growth model. 3. Grain growth, S. Afr. J. Plant Soil 8 (1991) 73-77.

[155] Singh U., Thomton P.K., Using crop models for sustainability and environmental quality assessment, Outlook Agric. 21 (1992) 209-218.

[156] Slabbers P.J., Practical prediction of actual evapotranspiration, Irrigation Sci. 1 (1980) 185-196.

[157] Slafer G.A., Rawson H.M., Development in wheat as affected by timing and length of exposure to long photoperiod, J. Exp. Bot. 46 (1995) 1877-1886.

[158] Stmith M., Allen R., Pereira L., Revised FAO methodology for crop water requirements, in: Camp C.R., Sadler E.J., Yoder R.E. (Eds,), Proceedings of the International Conference on Evapotranspiration and Irrigation Scheduling, 1996, pp. 116-124.

[159] Sonohat Popa G., Analyse des variations de structure aérienne de peuplements de maïs dans différentes conditions de compétition intraspécifique, thèse de doctorat, Université Paris XI, Orsay, France, 1997. I02 p. 
[160] Spaeth S.C., Sinclair T.R., Linear increase in soybean harvest index during seed-filling, Agron. J. 77 (1985) 207-211.

[161] Spitter C.J.T., Van Keulen H., Van Krealingen D.W.G., A simple and universal crop growth simulator: SUCROS87, in: Rabbinge R., Ward S.A., van Laar H.H. (Eds.), Simulation and Systems Management in Crop Protection, III, Simulation Monographs 32 (I) (1989) 47-177.

[162] Stapper M., Simtag: A Simulation Model of Wheat Genotypes. Model Documentation, ICARDA Publication, Aleppo, Syria, 1984.

[163] Steiner J.L., Smith R.C.G., Meyer W.S., Adeney J.A., Water use foliage temperature and yield of irrigated wheat in south-eastern Australia, Aust. J. Plant Physiol. 36 (1985) $1-11$.

[164] Stewart D.W., Dwyer L.M., A model of expansion and senescence of individual leaves of field-grown maize (Zea may.s L.), Can. J. Plant Sci. 74 (1990) 37-42.

[165] Stockle C.O., Kiniry J.R., Variability in crop radiation-use efficiency associated with vapor-pressure deficit, Field Crop. Res. 25 (1990) 171-181.

[166] Stutzel H., A simple model for simulation of growth and development in faba beans (Vicia faba L). I. Model description, Eur. J. Agron. 4 (1995) 175-185.

[167] Tardieu F., Manichon H., Caractérisation en tant que capteur d'eau de l'enracinement du maïs en parcelle cultivée. I. Discussion des critères d'étude, Agronomic 6 (1986) 345-354.

[168] Tardieu F., Bethenod O., Quels indicateurs du fonctionnement hydrique des plantes permettent de rendre compte des variations de rendement du maïs ?, in : Picard D. (éd.), Physiologie et production du maïs, Pau, 13-15 novembre 1990, 1991, pp. 319-328.

[169] Teittinen M., Karvonen T., Peltonen J., A dynamic model for water and nitrogen limited growth in spring wheat to predict yield and quality, J, Agron. I Crop Sci. / Z. Acker Pflanzenbau 172 (1994) 90-103.

[170] Thornley J.H.M., Modeling water in crops and plant ecosystems, Ann. Bot. 77 (1996) 261-275.

[171] Trapani N., Hall A.J., Sadras V.O., Vilella F., Ontogenetic changes in radiation use efficiency of sunflower (Helianthus annuus L) crops, Field Crop. Res. 29 (1992) 301-316.

[172] Uhart S.A., Andrade F.H., Nitrogen deficiency in maize. 1. Effects on crop growth development dry matter partitioning and kernel set, Crop Sci. 35 (1995) 1376-1383.
[173] Vachaud G., Vauclin M., Addiscott T.M., Solute transport in the vadose zone: a review of models, in: Avogadro A., Ragaini R.C. (Eds.), Technologies for Environmental Cleanup: Soil and Groundwater, ECSC, The Netherlands, 1993. pp. 157-185.

[174] Van der Ploeg R.R., Ringe H., Machulla G., Late fall site-specific soil nitrate upper limits for groundwater protection purposes, J. Environ. Qual. 24 (1995) 725-733.

[175] Van Diepen C.A., Wolf J.. Van Keulen H., Rappoldt C., WOFOST: a simulation model of crop production, Soil Use Manage. 5 (1989) 16-24.

[176] Van Keulen H., Seligman N.G., Simulation of Water Use Nitrogen Nutrition and Growth of a Spring Wheat Crop, Simulation Monograph, Pudoc, Wageningen, 1987.

[177] Van Lanen H.A.J., Hacktenbroeke M.J.D., Bouma J., Degroot W.J.M., A mixed qualitative quantitative physical land evaluation methodology, Geoderma 55 (1992) 37-54.

[178] Vanee G.R., Kline G.L., CORNSIM - a corn production model for central Iowa, Trans. ASAE 33 (1990) 757-763.

[179] Varcoe V.I., A note on the computer simulation of crop growth in agricultural land evaluation, Soil Use Manage. 6 (1990) 157-160.

[180] Varlet-Grancher C., Bonhomme R., Chartier M., Artis P., Efficience de la conversion de l'énergie solaire par un couvert végétal, Oecol. Plant. 3 (1982) $3-$ 26.

[181] Varlet-Grancher C., Gosse G., Chartier M., Sinoquet H., Bonhomme R., Allirand J.M., Mise au point : rayonnement solaire absorbé ou intercepté par un couvert végétal, Agronomie 9 (1989) 419-439.

[182] Vinten A.J.A., Redman M.H., Calibration and validation of a model of non-interactive solute leaching in a clay-loam arable soil, J. Soil Sci. 41 (1990) 199214.

[183] Weaich K., Cass A., Bristow K.L., Pre-emergent shool growth of maize (Zea mays L.) as a function of soil strength, Soil Till. Res. 40 (1996) 3-23.

[184] Weir A.H., Bragg P.L., Porter J.R., Rayner J.H., A winter wheat crop simulation model without water or nutrient limitations, J. Agric. Sci. 102 (1984) 371-382.

[185] Whisler J.R., Acock B., Baker D.N., Fye R.E., Hodges H.F., Lambert J.R., Lemmon H.E., McKinion J.M., Reddy V.R., Crop simulation models in agronomy systems, Adv. Agron. 40 (1986) 14I-208. 
[186] Williams J.R., Jones C.A., Dyke P.T., A modeling approach to Jetermining the relationship between erosion and soil productivity, Trans. ASAE 27 (1984) 129-144.

[187] Williams J.R., Jones C.A., Kiniry J.R., Spanel D.A., The EPIC crop growth model, Trans. ASAE 32 (1989) 497-511.
[1881 Wolf J., van Diepen C.A., Fffects of climate change on silage maize production in the European Community, Agric. For. Meteorol. 71 (1994) 33-60.

[189] Yokozawa M., Hara T., A canopy photosynthesis model for the dynamics of size structure and selfthinning in plant populations, Ann. Bot. 70 ( 1992) 305316.

\section{APPENDIX 1. List of equations.}

$\sum_{l=\pi, T}[(T S O L(P R O F S E M)-T G M I N) \times P F Z(P R O F S E M)]=S T P L T G E R$

$\left.E L O N G=E L M A X \mid 1-\exp \left(-\left(B E L O N G \times \sum_{l=\text { TLI:R }} \text { TSOL(PROFSEM }\right)-T G M I N\right)^{\text {CELONG }}\right]$

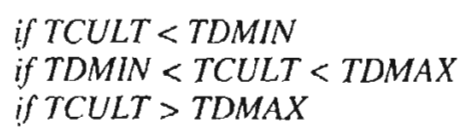

$J V I=1-0.4\left[1-\left.\frac{T C U L T}{6.5}\right|^{2}\right.$

$R F V I=\frac{\sum_{I=I G E R} J V I-7}{J V C-7}$

$R F P I=\frac{P H O I-P H O B A S E}{P H O S A T-P H O B A S E}$ and $0 \leq R F P I \leq 1$

TEAUGRAIN $=$ H2OGRMAT - DESSECGRAIN $\times \sum_{i=T M A T} T C U L T$ and IREC is for TEAUGRAIN $\leq$ H2OGRAIN

$$
\begin{aligned}
& D E L T A I=\frac{D L A I M A X}{1+\exp (5.5(2.2-U L A I))} \times(T C U L T-T C M I N) \times \min (T U R F A C, I N N S) \times E F D E N S I T E \times D E N S I T E \\
& \text { EFDENSITE }=\left(\frac{D E N S I T E}{B D E N S}\right)^{A D E N S} \\
& R A I N T=0.95 \times 0.50 \times T R G[1-\exp (-E X T I N \times L A I)] \\
& D L T A M S \times 100=\left[E B M A X \times R A I N T-0.0815 \times R A I N T^{2}\right] \times f(T C U L T) \times S W F A C \times I N N S \\
& \text { if } T C U L T<T C O P T \quad f(T C U L T)=1-\left(\frac{T C U L T-T C O P T}{T C M I N-T C O P T}\right)^{2} \\
& \text { if } T C U L T \geq T C O P T \quad f(T C U L T)=1-\left(\frac{T C U L T-T C O P T}{T C M A X-T C O P T}\right)^{2} \\
& N B G R A I N S=C G R A I N \times V I T M O Y+C G R A I N V O
\end{aligned}
$$




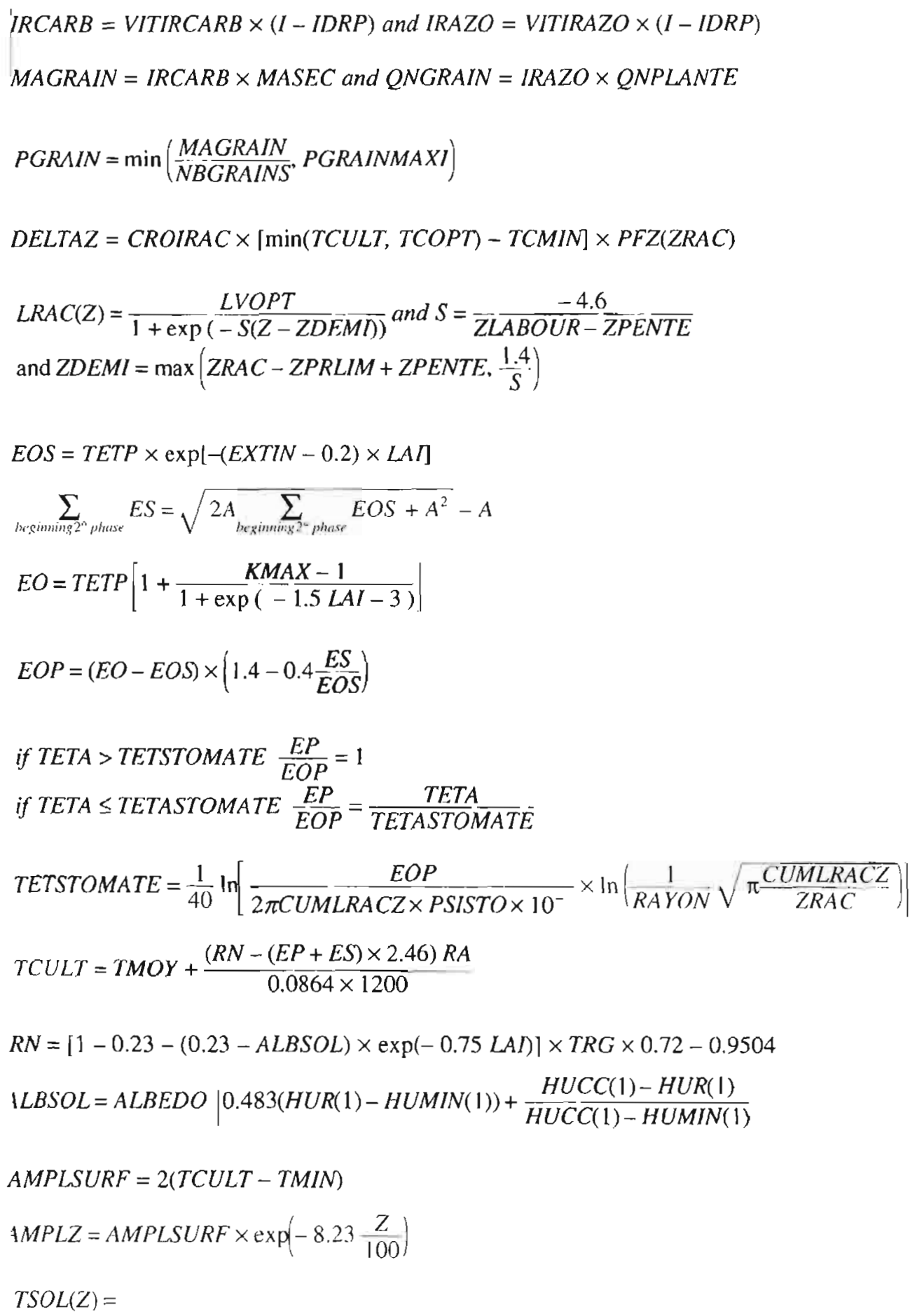




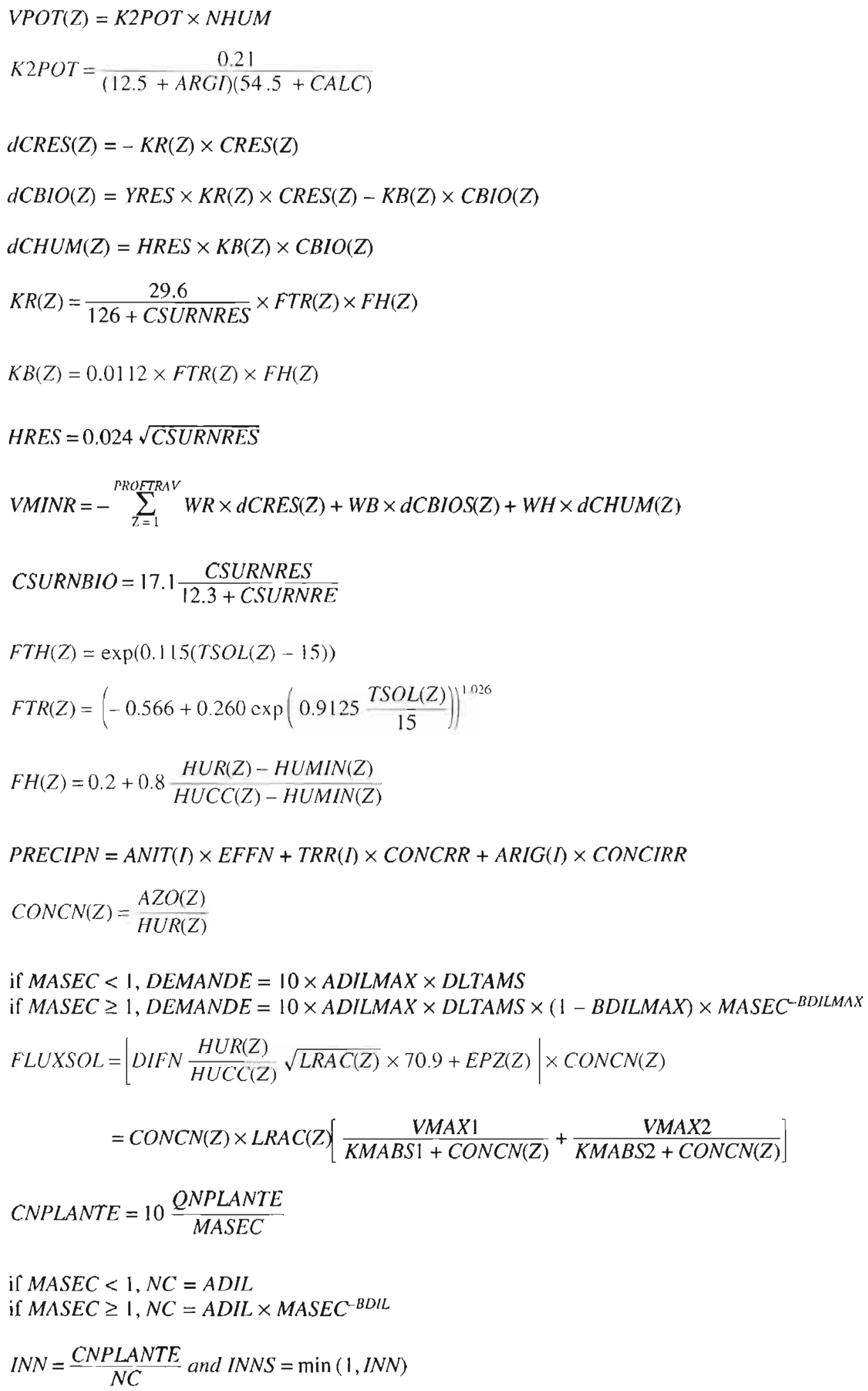




\section{APPENDIX 2. LIST OF SYMROLS IN THE TEXT.}

\section{Symbol}

A

ACLIM

ADENS

ADIL

ADILMAX

AIRG

ALBEDO

ALBSOL

AMPLSURF

AMPL7.

ANIT

ARGI

AZ (H)

AZO (Z)

BDENS

BDIL

BDILMAX

BEI.ONG

CALC

CBIO (Z)

CEILONG

CEP

CGRAIN

CGRAINVI)

CNGRAIN

CNPI_ANTE

CONCIRR

CONCN

CONCRR

CRES (Z)

CROIRAC

CSURNRES

CUMLRACZ

DA (H)

dCBIO (Z)

dCHUM (Z)

dCRES (Z)

DELTAI

DELTAZ

DEMANDE

DENSITE

DESSECGRAIN

DIFN

DI.AIMAX

DLTAMS
Meaning of the symbol

parameter of the soil evaporation during the reduction stage

climatic component of A

parameter of compensation between stem number

and plant density

parameter of the critical curve of nitrogen needs

parameter of the maximum curve of nitrogen needs

irrigation table

albedo of the bare dry soil

soil albedo

thermal amplitude at the soil surface

thermal amplitude at the depth $\mathrm{Z}$

fertilization table

percentage of clay in the surface layer

amount of mineral nitrogen in the horizon $\mathrm{H}$

amount of nitrogen in the layer $Z$

maximum density above which there is competition between

plants

parameter of the critical curve of nitrogen needs

parameter of the maximum curve of nitrogen needs

parameter of the curve of coleoptile elongation

percentage of limestone in the surface layer

amount of carbon in the biomass of the layer $\mathrm{Z}$

parameter of the curve of coleoptile elongation

transpiration integrated over the cropping season

slope of the relationship between grain number and growth rate

during the NBJGRAIN before stage IDRP

number of grains produced when growth rate is zero

nitrogen concentration of grains

nitrogen concentration of the plant

nitrogen concentration of irrigating water

nitrogen concentration of the solute of the soil

nitrogen concentration of precipitation

amount of carbon in the residues of the layer $Z$

growth rate of the root front

$\mathrm{C} / \mathrm{N}$ ratio of residues

sum of the effective root lengths

bulk density of horizon $\mathrm{H}$

daily changes in the $C$ content of the biomass pool

daily changes in the $\mathrm{C}$ content of the humus pool

daily changes in the $\mathrm{C}$ content of the residues pool

daily increase of the leaf index

deepening of the root front

daily nitrogen need of the plant

sowing density

drying rate of the grain

parameter of nitrogen diffusion in the soil

maximum rate of the setting up of LAI

growth rate of the plant
Units

and/or values

$\mathrm{mm}$

$\mathrm{mm}(20)$

sans dimension

$\mathrm{gN}$ g dry matter-1

gN g dry matter ${ }^{-1}$

mm day ${ }^{-1}$

sans dimension

sans dimension

${ }^{\circ} \mathrm{C}$

${ }^{\circ} \mathrm{C}$

$\mathrm{kg} \mathrm{N}$ ha $^{-1}$ day $^{-1}$

$\%$

kg N ha ${ }^{-1}$

$\mathrm{kg} \mathrm{N} \mathrm{ha}{ }^{-1} \mathrm{~cm}^{-1}$

$\mathrm{pl} \mathrm{\textrm {m } ^ { - 2 }}$

sans dimension

sans dimension

degree-day ${ }^{-1}$

$\%$

$\mathrm{kg} \mathrm{ha}^{-1} \mathrm{~cm}^{-1}$

sans dimension

$\mathrm{mm}$

grains g dry matter-1 day

grains $\mathrm{m}^{-2}$

gN g dry matter grain $^{-1}$

gN g dry matter ${ }^{-1}$

$\mathrm{kg} \mathrm{mm} \mathrm{m}^{-1}$

$\mathrm{kg} \mathrm{ha}^{-1} \mathrm{~mm}^{-1}$

$\mathrm{kg} \mathrm{mm}^{-1}$

$\mathrm{kg} \mathrm{ha}{ }^{-1} \mathrm{~cm}^{-1}$

$\mathrm{cm}$ degree-day ${ }^{-1}$

sans dimension

$\mathrm{cm}$ root $\mathrm{cm}^{-2}$ soil

$\mathrm{g} \mathrm{cm}^{-3}$

$\mathrm{kg} \mathrm{ha}^{-1}$ day $^{-1}$

$\mathrm{kg} \mathrm{ha}^{-1}$ day $^{-1}$

$\mathrm{kg} \mathrm{ha}^{-1}$ day $^{-1}$

$\mathrm{m}^{2}$ leaves $\mathrm{m}^{-2}$ soil day ${ }^{-1}$

$\mathrm{cm}$

$\mathrm{kgN} \mathrm{ha}^{-1}$ day $^{-1}$

$\mathrm{pl} \mathrm{\textrm {m } ^ { - 2 }}$

g water $\mathrm{g}$ fresh matter-1 ${ }^{\circ} \mathrm{C}^{-1}$

$\mathrm{cm}^{-2}$ day $^{-1}(0.21)$

$\mathrm{m}^{2}$ leaves $\mathrm{m}^{-2}$ soil degree days ${ }^{-1}$

I ha ${ }^{-1} \mathrm{day}^{-1}$ 


DRAIN
EBMAX
EFCROIREPRO
EFCROIVEG
EFDENSITE
EFFIRR
EFFN
ELMAX
ELONG
EO
EOP
EOS
EP
EPC (H)
EPZ (Z)
ES
EXTIN

FH

FLUXRAC FLUXSOL FTH

FTR

GPRECO
H2OGRAIN
II2OGRMAT
HA
HCC (H)
HMIN (H)
HR (H)
HUCC (Z)
HUMIN
HUR
I

IAMF

IDRP

ILAX

ILEV

IMAT

INN

INNS

IPLT

IRAZO

IRCARB

IREC

ISEN

JVC

JVI water flux drained out of the soil

maximum radiation use efficiency = EFCROIVEG or

EFCROIREPRO, according to the stage of the crop

maximum radiation use efficiency during the grain filling phase maximum radiation use efficiency during the vegetative stage density effect acting on the setting up of LAI

irrigation efficiency

fertilization efficiency

maximum elongation of the coleoptile in darkness condition

coleoptile elongation

intermediary variable for the computation of evapotranspiration

maximum transpiration flux

maximum evaporation flux

actual transpiration flux

thickness of the horizon $\mathrm{H}$

water absorption flux in the layer $Z$

actual soil evaporation flux

extinction coefficient of photosynthetic active radiation in the canopy

water content of the soil, correcting factor for the computation

of mineralization

biological component of the nitrogen absorption flux

component related to the transport of the nitrogen absorption flux $\mathrm{kgN} \mathrm{ha}^{-1} \mathrm{day}^{-1}$

temperature correction factor for the computation of humus

mineralization

temperature correction factor for the computation of residues

mineralization

variety identification number

water content of the grain when harvested

water content of the grain at physiological maturity

residual moisture of the soil

water content at the field capacity of the horizon $\mathrm{H}$

minimum water content of the horizon $\mathrm{H}$

water content of the horizon $\mathrm{H}$

volumetric water content of the layer $Z$ at the field capacity

minimum volumetric water content of the layer $Z$

volumetric water content of the layer $Z$

running day

day of the stage AMF : maximal acceleration of leaf growth, end of juvenile phase

day of the stage DRP: beginning of grain filling

day of the stage LAX: maximal leaf area index

day of the stage LEV: emergence

day of the stage MAT: physiological maturity

satisfaction of nitrogen needs

nitrogen stress index

date of sowing

nitrogen harvest index

carbon harvest index

day of the stage REC: harvest

day of the stage SEN: beginning of net senescence

number of vernalizing days

daily contribution to the vernalization $m m$ day $^{-1}$

t ha- $\mathrm{M}^{-1} \mathrm{~J}^{-1} \mathrm{~m}^{2}$

$\mathrm{g} \mathrm{MJ}^{-1}$

$\mathrm{g} \mathrm{MJ}^{-1}$

sans dimension

sans dimension

sans dimension

$\mathrm{cm}$

$\mathrm{cm}$

mm day ${ }^{-1}$

$\mathrm{mm}$ day $^{-1}$

$\mathrm{mm}$ day ${ }^{-1}$

$\mathrm{mm}$ day $^{-1}$

$\mathrm{cm}$

$\mathrm{mm} \mathrm{cm} \mathrm{cm}^{-1}$ day $^{-1}$

$\mathrm{mm}$ day $^{-1}$

sans dimension

sans dimension

$\mathrm{kgN} \mathrm{ha}^{-1} \mathrm{day}^{-1}$

sans dimension

sans dimension

$\mathrm{g}$ water $\mathrm{g}$ fresh matter grain ${ }^{-1}$

$\mathrm{g}$ water $\mathrm{g}$ fresh matter grain ${ }^{-1}$

$\mathrm{cm}^{3} \mathrm{~cm}^{-3}$

$\mathrm{g}$ water $\mathrm{g}$ soil ${ }^{-1}$

$\mathrm{g}$ water $\mathrm{g}$ soil $^{-1}$

g water $\mathrm{g}^{\mathrm{s}}$ soit-1

$\mathrm{mm} \mathrm{cm} \mathrm{cm}^{-\mathrm{i}}$

$\mathrm{mm} \mathrm{cm} \mathrm{cm}^{-1}$

$\mathrm{mm} \mathrm{cm}{ }^{-\mathrm{I}}$

sans dimension

sans dimension, between 0 and 1

$\mathrm{gN}$ grain gN plant ${ }^{-t}$

g grain $\mathrm{g}^{-1}$ plant 


\begin{tabular}{|c|c|c|}
\hline K2PO'T & daily potential rate of mineralization & day $^{-1}$ \\
\hline KB & mortality rate of the microflora & day $^{-1}$ \\
\hline KMABS1 & constant of nitrogen uptake by roots for the high affinity system & $\mu \mathrm{mol} \mathrm{cm}-1 \mathrm{~s}^{-1}$ \\
\hline KMABS2 & constant of nitrogen uptake by roots for the low affinity system & $\mu \mathrm{mol} \mathrm{cm}-1 \mathrm{~s}^{-1}$ \\
\hline KMAX & maximum crop coefficient for water requirements & sans dimension \\
\hline KR & decaying rate of the residues & day $^{-1}$ \\
\hline $\mathbf{L} \mathbf{A} \mathbf{I}$ & leaf area index & $\mathrm{m}^{2}$ leaves $\mathrm{m}^{-2}$ soil \\
\hline LATITUDE & latitudinal position of the crop & degrees and tenths \\
\hline LRAC (Z) & effective root density in the layer $\mathrm{Z}$ & $\mathrm{cm}$ root $\mathrm{cm}^{-3}$ soil \\
\hline LVOPT & optimum root density & $\mathrm{cm}$ root $\mathrm{cm}^{-3}$ soil $(0.5)$ \\
\hline MAGRAIN & dry matter of grains & $\mathrm{g} \mathrm{m}^{-2}$ \\
\hline MASEC & aboveground dry matter & t ha ${ }^{-1}$ \\
\hline MSAER0 & $\begin{array}{l}\text { threshold of aboveground dry matter corresponding to the root } \\
\text { allocation at the beginning of the cycle }\end{array}$ & t ha- \\
\hline NBGRAINS & grain number & grains $\mathrm{m}^{-2}$ \\
\hline NBJGRAIN & period when to compute NBGRAINS & number of days before IDRP \\
\hline NHUM & amount of nitrogen of the humus pool in the soil & $\mathrm{kg} \mathrm{ha}^{-1}$ \\
\hline PFZ (Z) & water status of the layer $\mathrm{Z}$ ( $=0$ if HUMIN, otherwise $=1$ ) & 0 or 1 \\
\hline PGRAIN & weight of one grain & $\mathrm{g}$ \\
\hline PGRAINMAXI & maximum weight of one grain ( $0 \%$ water content) & $\mathrm{g}$ \\
\hline PHOBASE & base photoperiod & hour \\
\hline PHOI & running photoperiod & hour \\
\hline PHOSAT & saturating photoperiod & hour \\
\hline PRECIPN & supply of fertilizer through precipitation or irrigation & $\mathrm{kgN} \mathrm{ha}^{-1} \mathrm{day}^{-1}$ \\
\hline PROFHUM & humification depth & $\mathrm{cm}$ \\
\hline PROFSEM & sowing depth & $\mathrm{cm}$ \\
\hline PROFSOL & soil depth & $\mathrm{cm}$ \\
\hline PROFTRAV & depth of residue incorporation & $\mathrm{cm}$ \\
\hline PSISTO & absolute value of the potential of stomatal closing & bars \\
\hline PSITURG & $\begin{array}{l}\text { absolute value of the potential of the beginning of decrease } \\
\text { of the cellular extension }\end{array}$ & ars \\
\hline Q0 & parameter of the end of the maximum cvaporation stage & $\mathrm{mm}$ \\
\hline QLES & sum of leached nitrogen & $\mathrm{kgN} \mathrm{ha}^{-\mathrm{l}}$ \\
\hline QMINH & sum of nitrogen mineralized from the humus & $\mathrm{kgN} \mathrm{ha}^{-1}$ \\
\hline QMINR & sum of nitrogen mineralized from residues & kgN hal \\
\hline QNGRAIN & amount of nitrogen in grains & $\mathrm{kgN} \mathrm{ha}^{-1}$ \\
\hline QNPLANTE & amount of nitrogen taken up by the plant & $\mathrm{kgN} \mathrm{ha}^{-1}$ \\
\hline RA & aerodynamic resistance & $\mathrm{sm}^{-1}(30)$ \\
\hline RAINT & photosynthetic active radiation intercepted by the canopy & $\mathrm{MJ} \mathrm{m}^{-2}$ \\
\hline RAYON & average radius of roots & $\mathrm{cm}(0.02)$ \\
\hline RFPI & slowing effect of the photoperiod on plant development & between 0 and 1 \\
\hline RFVI & slowing effect of the vernalization on plant development & between 0 and 1 \\
\hline $\mathbf{R N}$ & net solar radiation & $\mathrm{MJ} \mathrm{m}^{-2}$ \\
\hline $\mathbf{S}$ & parameter for the calculation of root density & $\mathrm{cm}^{-1}$ \\
\hline STAMFLAX & sum of development units between the stages AMF and LAX & degree-day \\
\hline STDRPSEN & sum of development units between the stages DRP and SEN & degree-day \\
\hline STLAXDRP & sum of development units between the stages LAX and DRP & degree-day \\
\hline STLEVAMF & sum of development units between the stages LEV and AMF & degree-day \\
\hline STMATREC & sum of development units between the stages MAT and REC & degree-day \\
\hline STPLTGER & sum of development units allowing germination & degree-day \\
\hline STSENMAT & sum of development units between the stages SEN and MAT & degree-day \\
\hline SWFAC & stomatal stress index & belween 0 and 1 \\
\hline TCMAX & maximum temperature of growth & ${ }^{\circ} \mathrm{C}$ \\
\hline
\end{tabular}




\begin{tabular}{|c|c|c|}
\hline TCMIN & minimum temperature of growth & ${ }^{\circ} \mathrm{C}$ \\
\hline TCOPT & optimum cemperature of growth & ${ }^{\circ} \mathrm{C}$ \\
\hline TCULT & surface temperature in daily average & ${ }^{\circ} \mathrm{C}$ \\
\hline TCULTVEILLE & TCULT on the day before & ${ }^{\circ} \mathrm{C}$ \\
\hline TDMAX & maximum threshold temperature for development & ${ }^{\circ} \mathrm{C}$ \\
\hline TDMIN & minimum threshold temperature for development & ${ }^{\circ} \mathrm{C}$ \\
\hline TEAUGRAIN & water content of the grain & $g$ water $g$ fresh grain \\
\hline TETA & water content of the soil, available to the plant & $\mathrm{cm}^{3} \mathrm{~cm}^{-3}$ \\
\hline TETP & reference evapotranspiration & mm day-1 \\
\hline TETSTOMATE & threshold of TETA below which SWFAC decreases & $\mathrm{cm}^{3} \mathrm{~cm}^{-3}$ \\
\hline TETURG & threshold of TETA below which TURFAC decreases & $\mathrm{cm}^{3} \mathrm{~cm}^{-3}$ \\
\hline TGMIN & minimum threshold temperature used in the emergence stage & ${ }^{\circ} \mathrm{C}$ \\
\hline TMIN & minimum temperature & ${ }^{\circ} \mathrm{C}$ \\
\hline TMOY & mean temperature & ${ }^{\circ} \mathrm{C}$ \\
\hline TRG & global solar radiation & $\mathrm{MJ} \mathrm{m}^{-2} \mathrm{day}^{-1}$ \\
\hline TRR & precipitation & mm day ${ }^{-1}$ \\
\hline TSOL $(\mathbf{Z})$ & temperature of the soil at the depth $\mathrm{Z}$ & ${ }^{\circ} \mathrm{C}$ \\
\hline TSOLVEILLE (Z) & temperature of the soil at the depth $Z$, on the day before & ${ }^{\circ} \mathrm{C}$ \\
\hline TURFAC & turgescence stress index & sans dimension between 0 and 1 \\
\hline UDEVCULT & $\begin{array}{l}\text { effective temperature for the development, computed with } \\
\text { TCULT }\end{array}$ & ${ }^{\circ} \mathrm{C}$ \\
\hline ULAI & $\begin{array}{l}\text { physiological time units for the calculation of the leaf arca index } \\
\text { between ILEV and ILAX }\end{array}$ & sans dimension between 1 and 3 \\
\hline VITIRAZO & rate of increase of the nitrogen harvest index & gN grain gN plant ${ }^{-1}$ day $^{-1}$ \\
\hline VITIRCARB & rate of increase of the carbon harvest index & g grain g plant ${ }^{-1}$ day $^{-1}$ \\
\hline VITMOY & $\begin{array}{l}\text { mean daily growth rate during the setting up of the grain number } \\
\text { (NBJGRAIN before the stage IDRP) }\end{array}$ & $\mathrm{g} \mathrm{m}^{-2} \mathrm{day}^{-1}$ \\
\hline VMAXI & rate of slow nitrogen absorption (high affinity system) & $\mu \mathrm{mol} \mathrm{cm}^{-1} \mathrm{~h}^{-1}$ \\
\hline VMAX2 & rate of rapid nitrogen absorption (low affinity system) & $\mu \mathrm{mol} \mathrm{cm}^{-1} \mathrm{~h}^{-1}$ \\
\hline VMINH $(\mathrm{Z})$ & rate of humus mineralization per layer & $\mathrm{kgN} \mathrm{ha} \mathrm{a}^{-1} \mathrm{~cm}^{-1} \mathrm{day}^{-1}$ \\
\hline VMINR & rate of residues organization & $\mathrm{kgN} \mathrm{ha}^{-1} \mathrm{day}^{-1}$ \\
\hline VPOT $(Z)$ & $\begin{array}{l}\text { potential rate of mineralization per layer at the reference } \\
\text { tempetature and water content }\end{array}$ & $\mathrm{kgN} \mathrm{ha} \mathrm{a}^{-1} \mathrm{~cm}^{-1} \mathrm{day}^{-1}$ \\
\hline WB & $\mathrm{N} / \mathrm{C}$ ratio of the microflora & $\mathrm{gN} \mathrm{gC}^{-1}$ \\
\hline WH & $\mathrm{N} / \mathrm{C}$ ratio of the humus & $\mathrm{gN}_{\mathrm{gC}}^{-1}$ \\
\hline WR & $\mathrm{C} / \mathrm{N}$ ratio of the residues remaining in the soil & $\mathrm{gC}_{\mathrm{gN}^{-1}}$ \\
\hline XMLCHI & mulch depth & $\mathrm{cm}$ \\
\hline YRES & carbon assimilation yjeld of the microflora & $\mathrm{g} \mathrm{g}^{-1}$ \\
\hline ZDEMI & depth where the root density is $1 / 2$ of the surface root density & $\mathrm{cm}$ \\
\hline ZLABOUR & depth of ploughing & $\mathrm{cm}$ \\
\hline ZPENTE & $\begin{array}{l}\text { depth where the root density is } 1 / 2 \text { of the surface root density } \\
\text { for the reference profile }\end{array}$ & $\mathrm{cm}$ \\
\hline ZPRLIM & maximum depth of the root profile for the reference profile & $\mathrm{cm}$ \\
\hline ZRAC & root depth & $\mathrm{cm}$ \\
\hline
\end{tabular}

